\title{
Temporal Sustainability Efficiency Analysis of Urban Areas via Data Envelopment Analysis and the Hypervolume Indicator: Application to London Boroughs
}

\author{
Authors

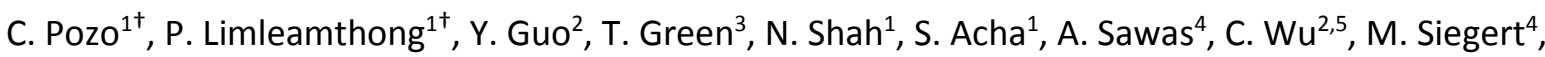 \\ G. Guillen-Gosálbez ${ }^{6 *}$
}

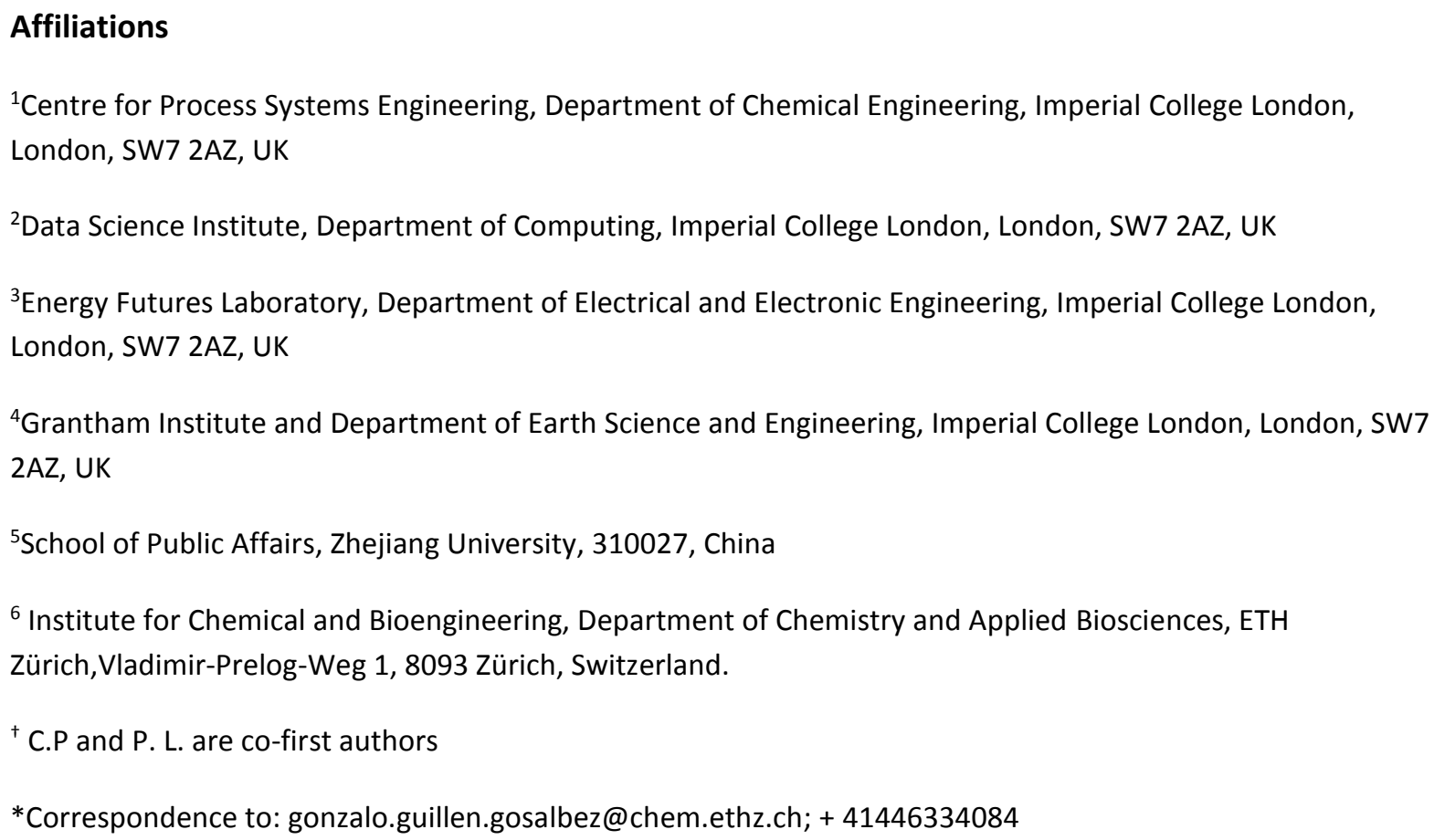

N.B.: This is the ACCEPTED MANUSCRIPT version of this article. The final, published version of the article can be found at: https://doi.org/10.1016/i.jclepro.2019.117839

\begin{abstract}
Transitioning towards a more sustainable society calls for systematic tools to assess the sustainability performance of urban systems. To perform this task effectively, this work introduces a novel method based on the combined use of Data Envelopment Analysis (DEA) and the hypervolume indicator. In essence, DEA is applied to (i) distinguish between efficient and inefficient urban systems through the identification of best practices; and to (ii) establish improvement targets for the inefficient urban systems that, if attained, would make them efficient. Meanwhile, the hypervolume indicator is employed in conjunction with DEA to evaluate how urban systems evolve with time. The capabilities of this approach are illustrated through its application to the sustainability assessment of London boroughs between the periods of 2012-2014. Results reveal that most boroughs tend to perform well
\end{abstract}


in terms of the indicators selected, with 20-25 of the 32 boroughs found efficient depending on the year. Regarding the temporal assessment, a global improvement in sustainability performance was found, with a strong relationship between boroughs' performances and their locations. The method proposed opens new pathways of social and environmental research for the application of advanced multi-criteria decision-support tools in the assessment and optimisation of urban systems.

\section{Keywords}

Data Envelopment Analysis; Hypervolume indicator; Temporal analysis; Sustainability; London Boroughs; Urban systems

\section{Introduction}

Sustainable urban transformation has been identified as one of the six key transformations necessary to achieve the Sustainable Development Goals (TWI2050 - The World in 2050, 2018). Catalysing this transition requires tools for assessing cities in terms of their economic, environmental and social performance, simultaneously. The evaluation of urban systems has been widely considered in the open literature, resulting in a plethora of indicators covering different angles of the problem (Goodland and Daly, 1996; Huang et al., 1998). In an effort to harmonise these sustainability metrics, the ISO 37120:2014 standard compiled 46 core and 54 supporting indicators, classifying them in 15 societal areas (e.g. economy, energy, environment, health, recreation and safety, etc.), and providing a general framework to track and monitor service performance and life quality in urban environments.

Analysing urban systems according to these sustainability indicators, the number of which can be quite high, is indeed a challenging task that calls for advanced multi-criteria decision-support tools. Among the methods available, Data Envelopment Analysis (DEA) (Charnes et al., 1978) has recently gained interest as it can deal with a wide range of criteria and identify potential opportunities for improvements in the worst-performing systems. DEA, originally developed in economics to evaluate entities converting several inputs into multiple outputs, has now evolved into a general benchmarking tool for multi-criteria decision-making (MCDM) (Cook et al., 2014). This method classifies a set of entities (Decision-Making Units, DMUs, in DEA notation) as efficient or inefficient, providing improvement targets for the latter that, if attained, would make them efficient. DEA shows some advantageous characteristics such as its nonparametric nature and the fact that it does not rely on any subjective weights to combine multiple indicators, which has favour its application in the environmental and sustainability assessment of a wide range of systems, including problems in agriculture (De Koeijer et al., 2002; Gomes et al., 2009), manufacturing (Egilmez et al., 2013; Zhang et al., 2008; Zofío and Prieto, 2001; Zurano-Cervelló et al., 2018), supply chain management (Babazadeh et al., 2017; Sueyoshi and Wang, 2014; Tajbakhsh and Hassini, 2015), and energy systems (Ewertowska et al., 2017, 2015; Martín-Gamboa et al., 2017; Sueyoshi et al., 2017; Zhou et al., 2008), among others.

The use of DEA in urban systems was pioneered by Charnes et al. (1989), who applied DEA to assess the economic performance of Chinese cities and assist the government's economic development program. More recently, Yu and Wen (2010) used DEA to evaluate the environmental sustainability of 46 Chinese cities in 2007, while Wang and Wei (2014) applied DEA to evaluate the regional energy and carbon emissions efficiency of the industrial sector in 30 Chinese cities during 2006-2010. 
The first DEA models are valid for performing static efficiency assessments in a given point in time. This kind of analysis might be insufficient in the case of cities, which are highly dynamic systems that can change substantially in short periods. Hence, a proper assessment of urban systems should provide as well the temporal evaluation of how the efficiency varies over time. Time-dependent analysis using DEA was first introduced by Klopp (1985), who proposed the so-called "window analysis". In this method, each DMU in each time period is modelled as a different DMU; several DEA problems are then solved for different (i.e. rolling) time horizons, and the efficiencies computed in the different runs are compared against each other. One limitation of this approach is that extreme time periods are evaluated less frequently than intermediate ones (Cooper et al., 2007). An alternative way to study how efficiency changes over time is to use the Malmquist productivity index (Malmquist, 1953), which has been widely applied to a plethora of systems (Caves et al., 1982; Färe et al., 1994; Färe and Grosskopf, 1992; Fernández et al., 2017), including urban environments (Yu and Wen, 2010). This method allows assessing both temporal changes in efficiency and shifts in the efficient frontier (i.e. the frontier defined by the linear combination of efficient DMUs), yet it presents two main shortcomings. First, it suffers from the same infeasibility issues as super-efficiency models (Seiford and Zhu, 1999), thus requiring the use of workarounds in order to obtain numerical values for some of the DMUs. Second, it only measures changes in the frontier around DMUs, thus failing to describe how the efficient frontier varies as a whole over time (further details provided in section 3.2).

In this contribution, a novel method to quantify the temporal evolution of the entire efficient frontier over time is proposed, ultimately providing insight into whether efficient units are becoming globally better or not. This method is based on the combined use of DEA and the hypervolume indicator, an index originally developed in the multi-objective optimisation literature to assess the quality of Pareto frontiers but, to the authors' knowledge, never applied before in conjunction with DEA. The capabilities of the method proposed are illustrated through its application to the assessment of London boroughs considering multiple sustainability criteria, while discussing its potential use by policy-makers in the sustainability assessment of urban systems.

The paper is organised as follows. A motivating example is introduced in section 2 to highlight the value of the proposed DEA-based approach. In section 3, the mathematical background underlying the method presented is described and then applied to the motivating example. A case study based on the sustainability evaluation of 32 London boroughs is illustrated in section 4, followed by some numerical results discussed in detail in section 5. Finally, the conclusions of the study are drawn in section 6 .

\section{Motivating Example}

This section introduces an illustrative example to motivate the use of the DEA-based approach proposed in this contribution for the multi-criteria assessment and monitoring of urban systems. Let us assume seven hypothetical cities, A-G, whose performance in terms of two indicators, namely, House Price and Life Satisfaction (see Table 1), need to be assessed over time (from period 1 to period 3). 
Table 1. Hypothetical city data exemplifying the DEA approach.

\begin{tabular}{|c|c|c|c|c|c|c|}
\hline \multirow{2}{*}{ Cities } & \multicolumn{2}{|c|}{ Period 1 } & \multicolumn{2}{c|}{ Period 2 } & \multicolumn{2}{c|}{ Period 3 } \\
\cline { 2 - 7 } & $\begin{array}{c}\text { House Price } \\
(\$)^{1}\end{array}$ & $\begin{array}{c}\text { Life } \\
\text { Satisfaction }^{2}\end{array}$ & $\begin{array}{c}\text { House Price } \\
(\$)\end{array}$ & $\begin{array}{c}\text { Life } \\
\text { Satisfaction }\end{array}$ & $\begin{array}{c}\text { House Price } \\
(\$)\end{array}$ & $\begin{array}{c}\text { Life } \\
\text { Satisfaction }\end{array}$ \\
\hline A & 297,845 & 7.05 & 304,504 & 7.09 & 340,387 & 7.01 \\
\hline B & 756,692 & 7.09 & 833,362 & 7.14 & 927,291 & 7.35 \\
\hline C & 358,778 & 7.42 & 370,613 & 7.42 & 407,187 & 7.28 \\
\hline D & 930,567 & 7.38 & $1,016,008$ & 7.21 & $1,137,178$ & 7.40 \\
\hline E & 620,714 & 7.43 & 640,563 & 7.28 & 693,046 & 7.40 \\
\hline F & 814,336 & 7.52 & 859,135 & 7.40 & 955,543 & 7.60 \\
\hline G & $1,715,451$ & 7.57 & $1,867,183$ & 7.70 & $2,099,844$ & 7.67 \\
\hline
\end{tabular}

The goal of the analysis is to answer the following questions, since this could assist municipal authorities in more effectively quantifying the progress made towards sustainable transformation:

- Which are the most efficient cities in transforming resources (e.g. House Price) into well-being (e.g. Life Satisfaction)?

- Which are the least efficient cities according to these criteria?

- By how much should the inefficient (worst-performing) cities be improved to become efficient?

- Are these cities becoming "globally better" or "globally worse" over time?

In an attempt to find answers, the data shown in Table 1 is next depicted in a Cartesian plot (see Fig. 1 below). The indicators House Price and Life Satisfaction are shown in the X-and Y-axis, respectively, while the circles in yellow, green, and blue represent the cities in periods 1, 2 and 3, respectively. The plot reveals that the first question can indeed be answered by identifying the set of cities whose performance cannot be improved in both indicators simultaneously. These cities (i.e. period 1: A, C, F, G; period 2: A, C, G; period 3: A, C, F, G) form an envelope that contain the other cities in each period, with the envelopes, i.e. the lines connecting all of the efficient cities in every period, being called efficient frontiers.

\footnotetext{
${ }^{1}$ The USD amount presented here was converted from GBP, as given in the original reference, by using the 2014 annual average exchange rate of 1.65073 USD per 11 (HM Revenue \& Customs, 2019).

2 Life Satisfaction presents as a score ranging from zero to ten, where zero is "not at all" and ten is

"completely".
} 


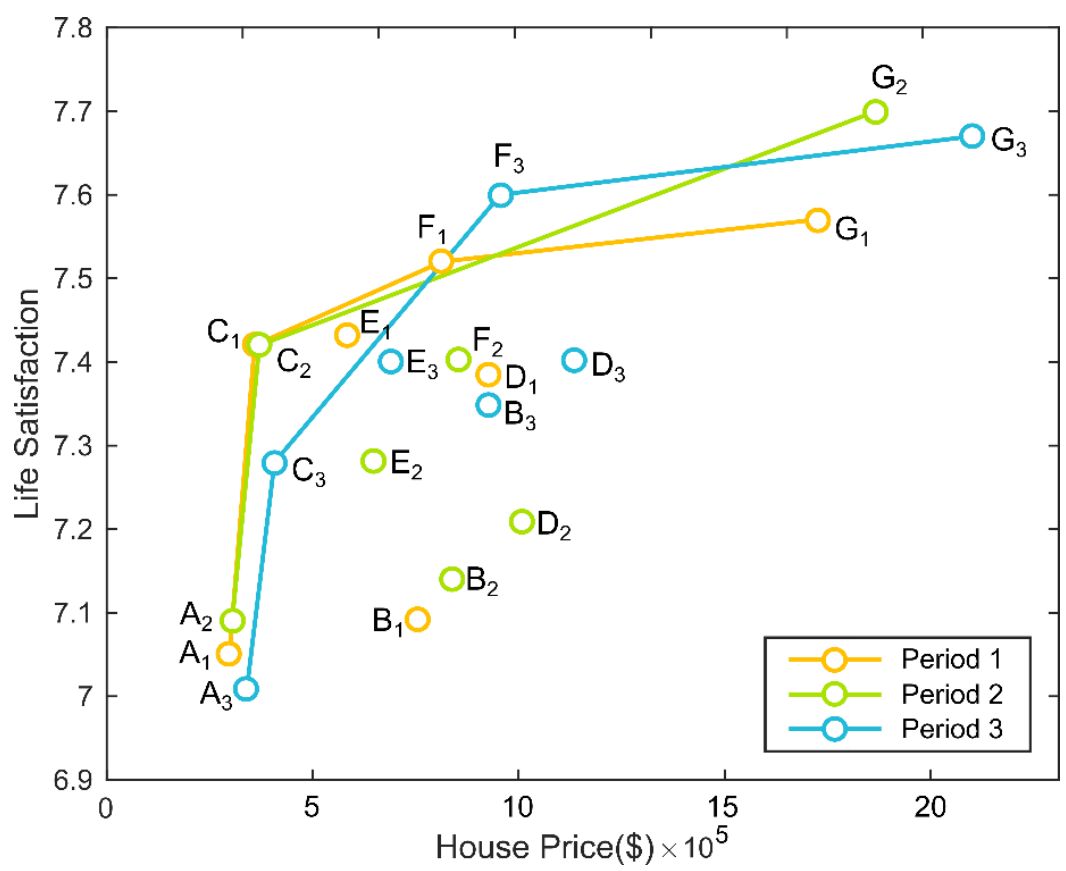

Fig.1. Graphical illustration of the motivating example.

For the other questions, a systematic approach with the capability of quantitatively measuring the sustainability performance of cities and their evolution over time is needed. In the next section, a novel methodological tool based on DEA is proposed to tackle this problem, with emphasis on its temporal dimension. Our method differs from the Malmquist productivity index in that the latter basically deals with a local analysis by considering efficiency changes of individual DMUs (i.e. it investigates how city $G$ has developed over periods 1 to 3 through the comparison of $G_{1}, G_{2}$, and $G_{3}$ with the corresponding efficient frontiers, as presented in Fig. 1); meanwhile, the proposed method focuses on the global evolution of the whole set of DMUs through the comparison of the efficient frontiers at specific periods (i.e. without considering any specific city such as $\mathrm{G}$ ).

\section{Methodology}

In this section, a standard DEA model for the static analysis of entities is first described and then applied to the motivating example presented earlier. Then, a tailored DEA-based hypervolume algorithm is proposed to assess the temporal evolution of entities over time. The latter aspect constitutes the main methodological novelty of this work. Further details on the fundamentals of DEA are delineated in the Supplementary material.

\subsection{Data Envelopment Analysis (DEA)}

\subsubsection{Efficiency model}

DEA is a data-driven technique developed to measure the relative efficiency of a set of homogeneous entities, commonly known as Decision Making Units (DMUs), each of them consuming multiple inputs to produce multiple outputs. Apart from entities traditionally assessed in economics, DMUs can also represent any type of system to be evaluated (i.e. London boroughs in this study), while inputs and outputs are the assessment criteria (i.e. sustainability indicators in this case). In a 
general benchmarking problem, the inputs usually correspond to the performance metrics to be minimised, while the outputs need to be maximised (Cook et al., 2014; Doyle and Green, 1993).

In essence, the original DEA model aims at maximising the efficiency of the unit being assessed (i.e. as given by the ratio of weighted sum of outputs to weighted sum of inputs), with weights attached to inputs and outputs not predefined by the user, but rather treated as decision variables whose values are optimised so as to maximise the efficiency score of the DMU assessed. Furthermore, this model can be linearised and dualised to obtain a DEA model in envelope form, which projects inefficient DMUs onto the efficient frontier, thus allowing the computation of improvement targets for them. Further details on DEA fundamentals are provided in the Supplementary material.

Since the development of the original DEA model, a considerable number of methodological variations and improvements have been put forward, for instance, slacks-based measures (Tone, 2001), assurance regions (Thompson et al., 1990), two-stage DEA (Chen et al., 2009) and three-phase DEA (Reynolds and Thompson, 2007), among others. These offer DEA practitioners the possibility to choose between different modelling alternatives in order to better represent the problem at hand. One such important modelling choice concerns the classification of indicators as discretionary and non-discretionary. Discretionary indicators can be varied in a freely discretionary manner. In contrast, non-discretionary indicators are exogenously fixed, yet they need to be appropriately modelled in the DEA formulation to compute the efficiency score precisely. Here, an input-oriented variable-returnsto-scale (VRS) DEA model in envelope form, including discretionary and non-discretionary inputs, is used to assess urban systems:

$$
\begin{aligned}
& \min _{\lambda_{j}, S_{i}^{-}, S_{r}^{+}} \theta_{o}-\varepsilon\left(\sum_{i \in D} S_{i}^{-}+\sum_{r=1}^{S} S_{r}^{+}\right) \\
& \text {s.t. } \quad \sum_{j=1}^{n} \lambda_{j} x_{i j}+S_{i}^{-}=\theta_{o} x_{i o} ; \quad \forall i \in D \\
& \sum_{j=1}^{n} \lambda_{j} x_{i j}+S_{i}^{-}=x_{i o} ; \quad \forall i \in N D \\
& \sum_{j=1}^{n} \lambda_{j} y_{r j}-S_{r}^{+}=y_{r o} ; \quad \forall r \in R \\
& \lambda_{j}, S_{i}^{-}, S_{r}^{+} \geq 0 ; \quad \forall i, j, r ; \quad \theta_{o} \text { unconstrained } .
\end{aligned}
$$

where the notation used is as follows:

Indices:

$o$ Index for the DMU that is being assessed $(o=1, \ldots, n)$

$j \quad$ Index for DMUs $j=1, \ldots, n$ (including $j=o$ )

$i$ Index for the criteria classified as inputs $(i=1, \ldots, m)$

$r$ Index for the criteria classified as outputs $(r=1, \ldots, s)$

Sets:

$J$ Set of DMUs

$D$ Set of discretionary inputs

$N D$ Set of non-discretionary inputs

$R$ Set of outputs

Parameters (data given by users): 
$x_{i j}$ Amount of input $i(i=1, \ldots, m)$ consumed by $\mathrm{DMU}_{j}$

$y_{r j}$ Amount of output $r(r=1, \ldots, s)$ produced by $\mathrm{DMU}_{j}$

$\varepsilon \quad$ Non-Archimedean infinitesimal value to enforce the variables to be strictly positive

Variables (computed by DEA):

$\theta_{o}$ Relative efficiency score of $\mathrm{DMU}_{\text {。 }}$

$S_{i}^{-}$Slack variables for input $i$, surplus amount of input that needs to be reduced to become strongly efficient

$S_{r}^{+}$Slack variables for output $r$, additional amount of output that needs to be increased to become strongly efficient

$\lambda_{j}$ Linear weights attached to every single $\mathrm{DMU}_{\mathrm{j}}$ to form a linear combination

Compared to the original DEA model, this alternative is different in two ways: (i) nondiscretionary inputs are not radially projected and, consequently, they are not multiplied by the efficiency variable $\theta_{o}$; (ii) the slacks of the non-discretionary inputs $S_{i}^{-}, i \in N D$, are excluded from the objective function, so they are not considered in the efficiency assessment.

According to model M.1, a DMU will be classified as efficient if its efficiency score $\theta_{o}^{*}$ is equal to one and as inefficient if it is strictly less than one. Furthermore, this model provides the reference set of each inefficient DMU (also called peer group), composed of those efficient DMUs with strictly positive linear coefficients $\lambda_{j}^{*}$. Hence, the optimal solution of M.1 can be used to compute the targets and percentage improvements required by inefficient DMUs to become efficient:

Target for discretionary input $i$ is given by $\sum_{j=1}^{n} \lambda_{j}^{*} x_{i j}=\theta_{o}^{*} x_{i o}-S_{i}^{-*}$

Target for non-discretionary input $i$ is given by $\sum_{j=1}^{n} \lambda_{j}^{*} x_{i j}=x_{i o}-S_{i}^{-*}$

Target for output $r$ is given by $\sum_{j=1}^{n} \lambda_{j}^{*} y_{r j}=y_{r o}+S_{r}^{+*}$

$\%$ Improvement required in discretionary/non-discretionary input $i$ is $\frac{\left(\sum_{j=1}^{n} \lambda_{j}^{*} x_{i j}\right)-x_{i o}}{x_{i o}} \times 100 \%$ (eq.4)

$\%$ Improvement required in output $r$ is $\frac{\left(\sum_{j=1}^{n} \lambda_{j}^{*} y_{r j}\right)-y_{r o}}{y_{r o}} \times 100 \%$

\subsubsection{Super-efficiency model}

Traditional DEA models can effectively distinguish between efficient and inefficient units; however, efficient units, all with an efficiency score of one, cannot be further ranked. This leads to a low discriminatory power that can be overcome using the super-efficiency concept. The superefficiency of a DMU can be computed with the super-efficiency DEA model, which is essentially the same as the standard efficiency DEA model but excludes the DMU being assessed from the reference set. Hence, the mathematical expression of this model contains the same equations as shown in M.1, but the efficient unit under evaluation is not included in the summation of lambdas. In other words, let $o$ be the efficient unit for which the super-efficiency is determined, then the constraints in model M.1 are reformulated as follows: 


$$
\min _{\lambda_{j}, S_{i}^{-}, S_{r}^{+}} \theta_{o}^{S E}-\varepsilon\left(\sum_{i \in D} S_{i}^{-}+\sum_{r=1}^{S} S_{r}^{+}\right)
$$

s.t. $\quad \sum_{j=1, j \neq o}^{n} \lambda_{j} x_{i j}+S_{i}^{-}=\theta_{o}^{S E} x_{i o} ; \quad \forall i \in D$

$$
\sum_{j=1, j \neq o}^{n} \lambda_{j} x_{i j}+S_{i}^{-}=x_{i o} ; \quad \forall i \in N D
$$

$$
\sum_{j=1, j \neq o}^{n} \lambda_{j} y_{r j}-S_{r}^{+}=y_{r o} ; \quad \forall r \in R
$$

$$
\lambda_{j}, S_{i}^{-}, S_{r}^{+} \geq 0 ; \quad \forall i, j, r ; \quad \theta_{o} \text { unconstrained }
$$

For each efficient DMU, the model provides a super-efficiency score $\theta_{O}^{S E}$ that is always greater than or equal to one. The super-efficiency score quantifies the extent to which the efficient frontier changes when the efficient unit assessed is removed from the pool (i.e. higher super-efficiencies imply more drastic changes). Since the input-oriented model is assumed, super-efficiency provides a measure of the extra-savings that the efficient DMU being assessed attains in its inputs (i.e. the difference between the current values of the inputs and the threshold that, if surpassed, would make the DMU inefficient; see (Chen, 2005; Seiford and Zhu, 1999) for further details). Therefore, this approach provides a ranking of efficient units without the need to define subjective weights on inputs and outputs.

\subsubsection{Motivating example revisited}

DEA is next applied to the motivating example introduced earlier in order to obtain efficiency scores and improvement targets for the different cities. To this end, the attribute House Price is modelled as a discretionary input, while Life Satisfaction is modelled as an output. Results reveal that there are four efficient cities in period 1 , namely $A, C, F$, and $G$ (yellow bars in Fig. 2), and three inefficient cities, namely $B, D$, and $E$ (blue bars in the same Fig.).

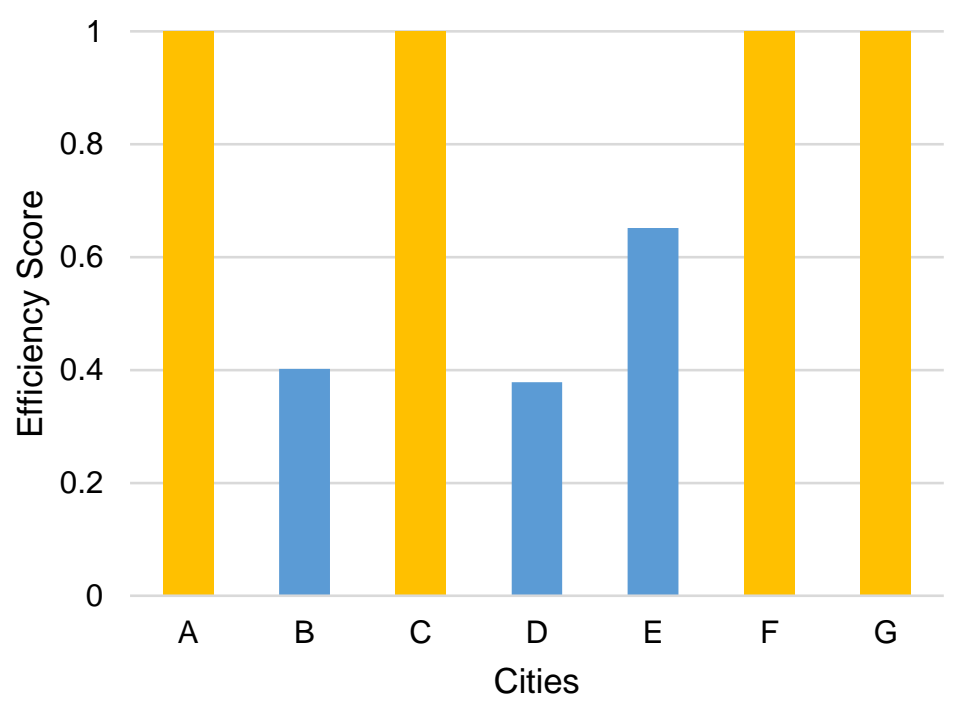

Fig. 2. Bar graph showing the efficiency score attained in period 1 by the seven cities in the motivating example.

The efficient frontier for the same period is given in Fig. 3, showing how the inefficient cities can be projected onto the efficient frontier in order to improve their performance. The efficient 
frontier is derived from the efficient cities as the piecewise linear function $\overline{A C F G}$. For each inefficient city, this projection defines a hypothetical city using a linear combination of its peers that shows at least the same Life Satisfaction and lower House Price (input-oriented projection). As an example, city D could become efficient by keeping its Life Satisfaction level of 7.38, while reducing its average House Price from $\$ 930,568(£ 563,731)$ (denoted by a blue circle) to its target $D^{\prime}$ of $\$ 352,190(£ 213,354)$ (denoted by a green circle).

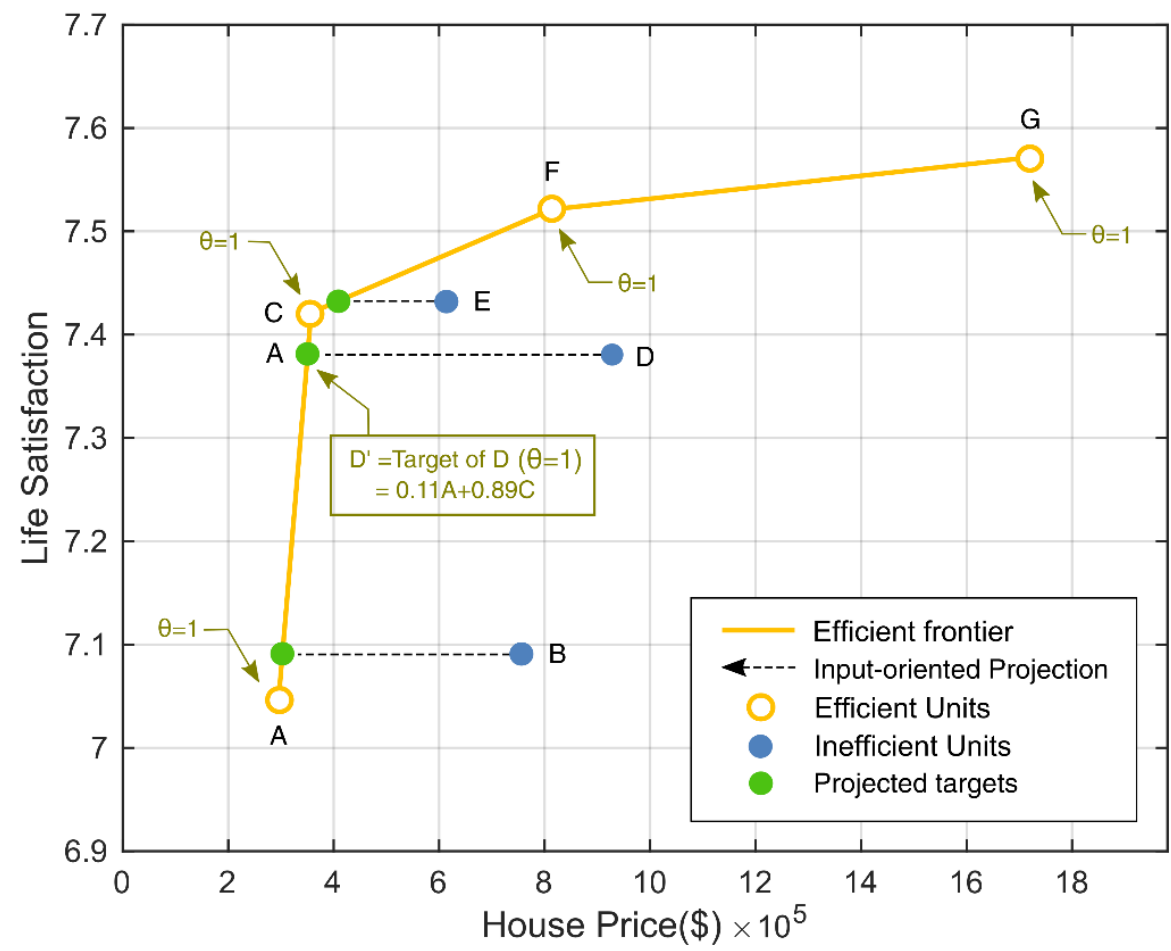

Fig. 3. Illustrative example of how DEA would be applied for period 1 in the motivating. Efficient cities are combined to provide the efficient frontier, whereas inefficient units are projected onto this frontier radially in their inputs.

Analogously, DEA could also be used to quantify efficiency scores and improvement targets for the seven cities in periods 2 and 3, thus answering the second and the third questions we posed when we presented the motivating example (section 2). However, the method still provides no clue on how these cities evolved with time, leaving the fourth question unanswered. The next section presents the novel method we propose to perform the temporal analysis of global changes in an efficient frontier, where DEA fundamentals and the hypervolume indicator are used as a basis.

\subsection{Temporal analysis of efficient frontiers}

DEA was originally devised for analysing static data at a given instant of time, but not for temporal data series (Malmquist, 1953). Some dynamic extensions of DEA have been put forward, yet they have primarily focused on quantifying the temporal evolution of each individual DMU rather than on the analysis of global changes in the efficient frontier. With the latter in mind, a novel methodological approach is proposed here, providing insight into how the set of efficient units defining the efficient frontier vary, overall, in a given time period. This insight, complemented by the 
outcome of the standard DEA, can be very useful for decision-makers seeking to assess the effectiveness of policies and regulations on urban systems.

In this study, the performance of the efficient frontier, as a whole, at a specific time instant is measured by means of the hypervolume indicator (also known as Lebesgue or $\mathrm{S}$ metric), where a larger value indicates that the efficient frontier has globally improved, as it dominates more points in the feasible objectives space. The comparison of hypervolume values across periods provides insight into the shifts of the efficient frontier during that period. Hence, an increase in the hypervolume indicator implies that the DMUs are becoming "globally" more efficient, so the efficient frontier is progressing over time as a whole.

Originally introduced by Zitzler and Thiele (1998), the hypervolume indicator has been traditionally applied to assess the numerical performance of multi-objective algorithms (Beume et al., 2007; Copado-Méndez et al., 2016; Zitzler et al., 2007) given its appealing theoretical properties (see Zitzler et al. (2003)). The hypervolume measures the size of the dominated $d$-dimensional space between a Pareto frontier defined by a set of points $q^{\prime}$ and a reference (dominated) point $q_{\text {ref }}$ (Chatterjee, 2003) (see Fig. 4a). The formal definition is as follows:

$$
\pi^{d}=\left\{q \in \mathbb{R}^{d+}: q^{\prime} \preccurlyeq q \preccurlyeq q_{r e f}\right\}
$$

The hypervolume, graphically shown in Fig. 4a, is computed from the set of Pareto optimal points (in this case DMUs A-E, denoted by blue circles) and a reference dominated point $q_{\text {ref }}$ (depicted with a red circle). Unfortunately, the calculation of the hypervolume requires the solution of multidimensional integrals and, for this reason, is in itself time consuming (and even more so as the number of indicators increases) (Beume and Rudolph, 2006). One way to simplify the calculations is to approximate the hypervolume following the algorithm proposed by Everson et al. (2002) (see Fig. 4b). This approach first applies sampling methods to generate randomly distributed points, and then counts the number of them contained in a set of hyperrectangles defined between the Pareto points $q^{\prime}$ (upper leftmost coordinate of the hyperrectangle, see Fig. 4b) and a reference point $q_{\text {ref }}$ (lower rightmost coordinate). Fig. $4 \mathrm{~b}$ illustrates how this method works, where green points correspond to random samples dominated by efficient points $q^{\prime}$, while purple points are the ones not dominated. By computing the ratio between the green and the total number of points, an approximation to the area enclosed between the efficient points and the reference point (i.e. the hypervolume value) can be obtained, which is used to measure the quality of the efficient frontier. 


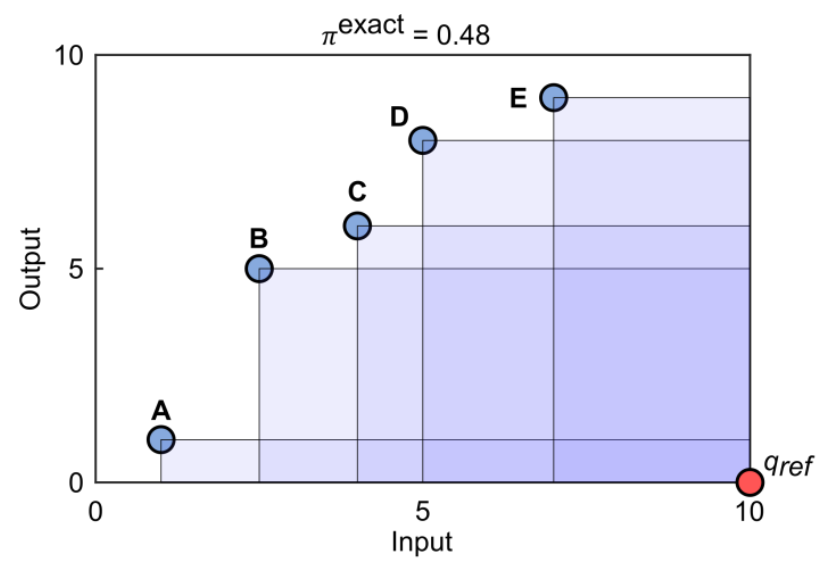

a) Original hypervolume

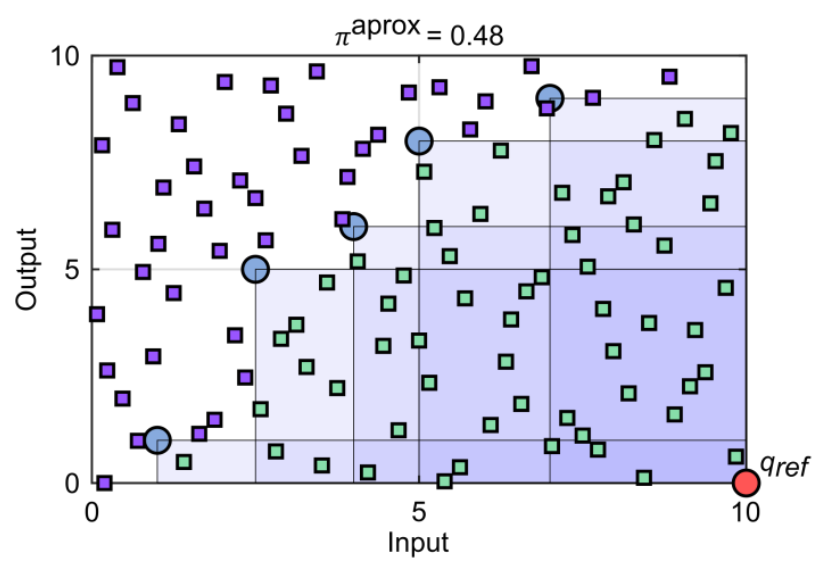

b) Everson et al. (2002)

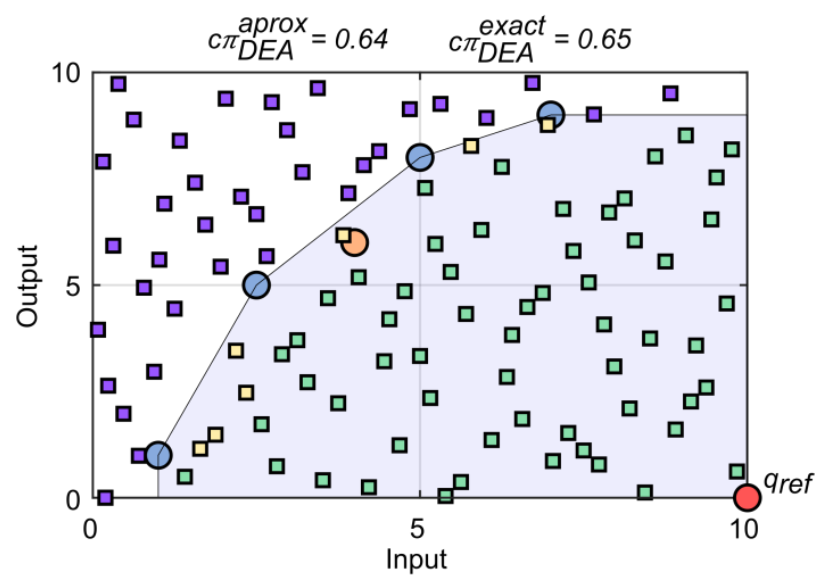

c) Proposed method

Pareto points $q^{\prime}$ (DMUs here)

O Reference point $q_{r e f}$

O Pareto points, dominated in DEA
- Dominated random points

a Non-dominated random points

口 Non-dominated random points, inefficient in the context of DEA

Fig.4. Illustrative example of alternative hypervolume calculations.

Comparing to the aforementioned algorithm, the method proposed here is novel and distinct in three alternative ways that significantly affect the hypervolume estimation: (i) in how the efficient frontier is defined (DEA-based instead of Pareto-based); (ii) in how samples are generated; and (iii) in 
the option of computing hypervolume values for tailored regions of the search space. These three aspects of the algorithm are described in detail next.

\subsubsection{Characterisation of the efficient frontier}

Everson's algorithm assesses the hypervolume of the Pareto front by using a set of discrete Pareto points. In contrast, the aim here is to compute the hypervolume of a continuous efficient frontier, as given by the convex envelope of the efficient DMUs. This convex envelop is essentially the linear combination of the efficient DMUs identified by DEA, so it potentially contains an infinite number of points $q^{\prime}$. Hence, the hypervolume metric sought in DEA can be mathematically defined as follows:

$$
c \pi_{D E A}^{m+r}=\left\{q \in \mathbb{R}^{m+r}: \sum_{j \in E D M U} \lambda_{j} q_{j} \preccurlyeq q \preccurlyeq q_{r e f}, \sum_{j \in E D M U} \lambda_{j}=1, \lambda_{j} \geq 0\right\}
$$

where EDMU is the set of efficient DMUs, as determined by problem M.1, $\lambda_{j}$ are linear coefficients and $q_{j}$ is the point denoted by the input and output coordinates of DMU $j$.

Note that, in DEA, those Pareto points lying on the nonconvex part of the Pareto front are considered inefficient and, therefore, are excluded from the efficient frontier. For example, DMU $C$ is considered Pareto optimal (see Fig. 4a), but is deemed inefficient (i.e. not VRS efficient, see Supplementary material) in the DEA approach (see Fig. 4c); this happens because it lies below the convex envelope of the efficient units.

In addition, Everson's hypervolume algorithm would rely on discrete samples of the DEA efficient frontier to generate points $q^{\prime}$ used to approximate the hypervolume. In this regard, the degree of discretisation (i.e. the sample size) can strongly affect the quality of the hypervolume approximation. In contrast, the proposed hypervolume algorithm (see Fig. 4c) does not rely on any set of discrete points $q^{\prime}$ but rather makes use of the DEA models to distinguish between non-dominated (i.e. efficient) and dominated (i.e. inefficient) points by benchmarking them against the DEA-based efficient frontier. In essence, a DEA model is solved for each random point to determine whether it is or not dominated by the DEA efficient frontier.

Following this approach, $|T|$ random points $\left(q_{t}\right)$ are generated first, and then an inputoriented VRS DEA model is solved for each of them to obtain their corresponding efficiency score $\left(\theta_{t}^{*}\right)$ and determine whether the point is dominated or not by the DEA efficient frontier. This problem can be mathematically expressed as follows:

$$
\begin{array}{lll}
\min _{j, S_{i}^{-}, S_{r}^{+}} & \theta_{t}-\varepsilon\left(\sum_{i \in D} S_{i}^{-}+\sum_{r=1}^{S} S_{r}^{+}\right) & \\
\text {s.t. } & \sum_{j \in E D M U} \lambda_{j} x_{i j}+S_{i}^{-}=\theta_{t} x_{i t} ; & \forall i \in D \\
& \sum_{j \in E D M U} \lambda_{j} x_{i j}+S_{i}^{-}=x_{i t} ; & \forall i \in N D \\
& \sum_{j \in E D M U} \lambda_{j} y_{r j}-S_{r}^{+}=y_{r t} ; \quad & \forall r \in R \\
& \lambda_{j}, S_{i}^{-}, S_{r}^{+} \geq 0 ; \quad \forall i, j, r ; & \theta_{o} \text { unconstrained. }
\end{array}
$$


If $\theta_{t}^{*}<1$, then $q_{t}$ is dominated by the efficient frontier (green and yellow squares in Fig. 4c). Conversely, if $\theta_{t}^{*} \geq 1$ or the problem is infeasible, then $q_{t}$ is a non-dominated point (denoted by purple squares in the figure). The hypervolume indicator is then computed as the ratio of the total number of dominated (i.e. inefficient) points to the total number of random testing points. By using the proposed method instead of that in Everson et al. (2002), the testing points located in the non-convex region of the Pareto-based hypervolume (depicted with yellow squares in Fig. 4c) are counted towards the hypervolume of the DEA frontier.

Note that problem (M.3) is analogous to the super-efficiency DEA model, in the sense that the point being assessed is analysed taking as reference an efficient frontier constructed without that particular point. As a result, the model can be infeasible in some particular cases; for instance, when the randomly generated point $q_{t}$ shows an output value above the maximum output values across the DMUs belonging to the set EDMU. Therefore, if problem (M.3) is infeasible, it implies that $q_{t}$ is nondominated. The interested reader is referred to $($ Chen, 2005) for further details on this topic.

\subsubsection{Sampling points generation}

The second distinction of the proposed approach is the use of a pseudorandom sequence, instead of a random one as in Everson's case, to generate the points used in the analysis, as previously demonstrated by Copado-Méndez et al. (2016). The motivation for this is that pseudorandom sequences show higher discrepancy compared to random ones (Bratley et al., 1992). Without loss of generality, the Halton sequence is employed, yet others such as the Sobol one could also be used in the general framework proposed.

\subsubsection{Regional hypervolume analysis}

Finally, computing different hypervolumes allows to investigate changes in the efficient frontier for a particular range of inputs or outputs. We, therefore, introduce the option of computing the hypervolume for different regions of the search space $A P^{m+r}\left(c \pi_{D E A, A P}^{m+r}\right)$, as shown below:

$$
A P^{m+r}=\left\{q \in \mathbb{R}^{m+r}: q_{\text {ref } A}^{m+r} \preccurlyeq q \leqslant q_{\text {ref } B}^{m+r}, 0^{m+r} \preccurlyeq q_{\text {ref } A}^{m+r}, q_{\text {ref } B}^{m+r} \leqslant q_{\text {ref }}^{m+r}\right\}
$$

where $q_{r e f A}^{m+r}$ and $q_{r e f B}^{m+r}$ are the bounds delimiting the specific region of the search space to be assessed. To this end, pseudorandom points are generated only within bounds $q_{r e f A}^{m+r}$ and $q_{r e f B}^{m+r}$, thus providing an approximation of the hypervolume in that sub-region. This topic is further discussed in the case study section.

\subsubsection{Proposed algorithm}

The overall algorithm for the hypervolume calculation is shown in Fig. 5. The algorithm starts by setting the number of dominated points to zero and defining the boundaries of the region for which the hypervolume will be computed (i.e. $q_{r e f A}^{m+r}$ and $q_{r e f B}^{m+r}$ ). In this contribution, these boundaries are established as the lower and upper bounds (i.e. minimum and maximum values) of each indicator (i.e. input/output) across the periods analysed. Then, $|T|$ pseudorandom points are generated within these boundaries and a loop is started for each of the points. In each iteration, model M.3 is solved to check whether the pseudorandom point is dominated by the DEA efficient frontier. If so, then the number of dominated (i.e. inefficient) points is increased by one and the algorithm moves to the next iteration; otherwise, the algorithm moves to the next iteration leaving the counter used for the number of dominated points unaltered. At the end, the ratio between the number of dominated 
points to the number of total points is used to approximate the "real" hypervolume value that would be obtained through an exact analytical integral.

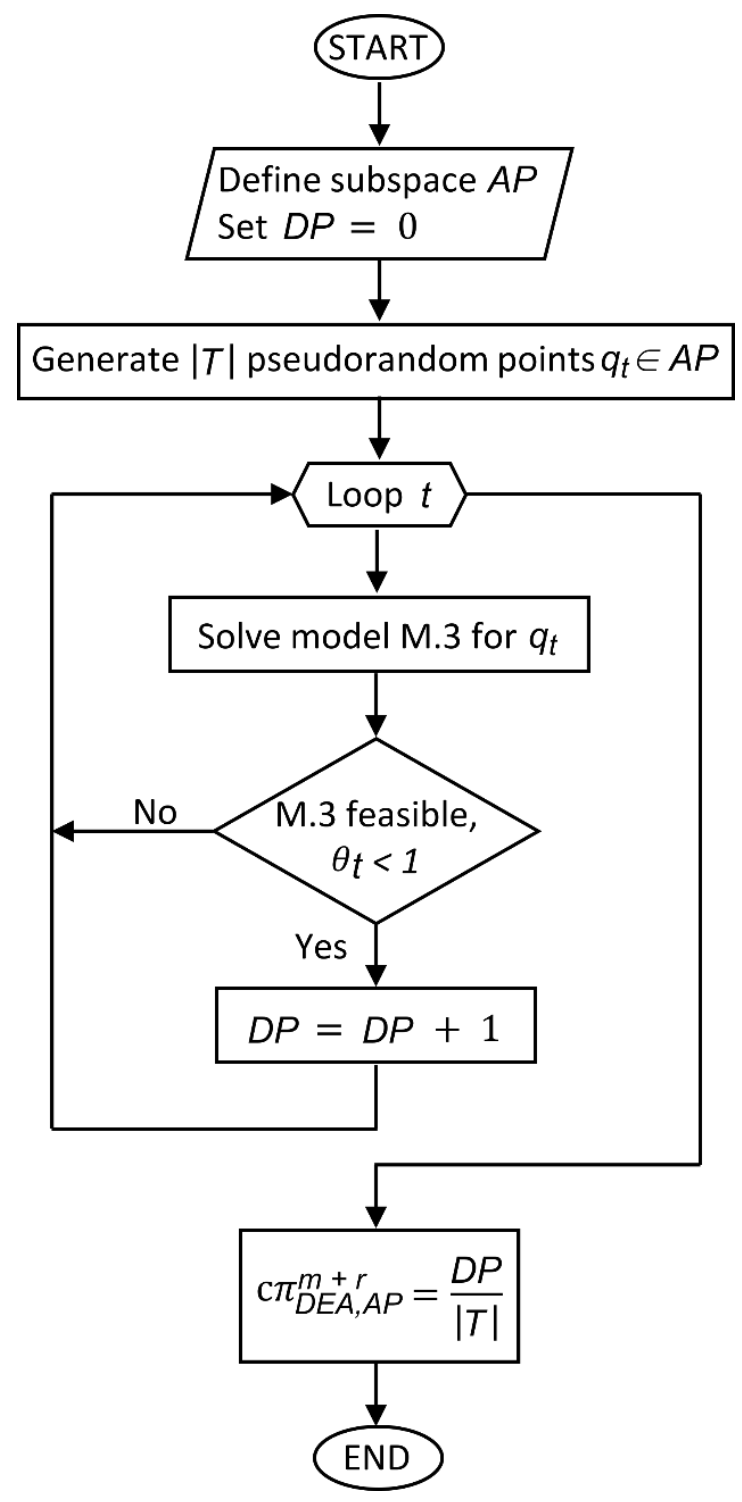

Fig. 5. Flowchart of the proposed algorithm to approximate the hypervolume of an efficient frontier $c \pi_{D E A, A P}^{m+r}$ in a certain region of the space $A P$. Note that two conditions must be satisfied simultaneously in the decision step; namely that the model is feasible and that the efficiency score of the point assessed is strictly lower than one.

\subsubsection{Temporal analysis of the motivating example}

The motivating example is once more revisited to examine the temporal evolution of the efficient frontiers from period 1 to period 3. Fig. 6 shows the efficient frontiers emerging in each period. As seen, comparing them is challenging because they intersect with each other. For example, the frontier in period 1 (denoted by a yellow line) shows the best Life Satisfaction for House Prices between $\$ 297,131$ (corresponding to $£ 180,000)$ and $\$ 825,365(£ 500,000)$ whereas the frontier for period 2 (depicted in green) is superior in the range of $\$ 1,485,657-\$ 1,865,325$ (£900,000 $£ 1,130,000$ ), and the frontier in period 3 (in blue) dominates for the rest of the House Prices. Hence, 
no clear general conclusions can be drawn at a first glance from their visual analysis, even in the twodimensional case; this highlights the need to develop a tool for quantitatively measuring the quality of the efficient frontier according to multiple criteria.

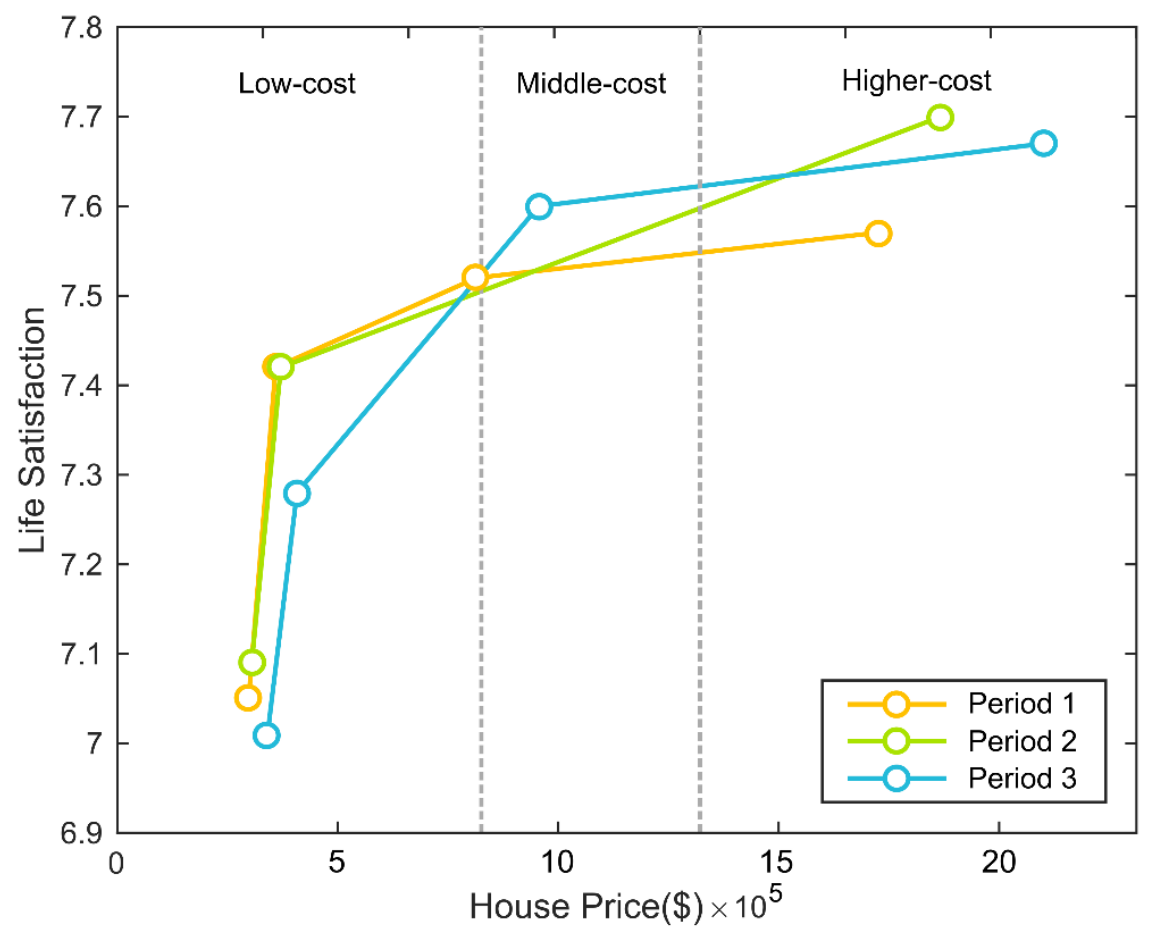

Fig. 6. Temporal analysis of efficient frontiers of seven cities for periods one to three.

In the context of DEA, the Malmquist index (the readers could refer to (Malmquist, 1953)) is the start-of-the art tool for performing temporal analysis of DMUs. For each particular $\mathrm{DMU}_{0}$, the Malmquist index provides the productivity change between periods $t$ and $t+1$, which can in turn be decomposed into two terms: one term (TEC $C_{0}$ ) measuring changes in the technical efficiency of $\mathrm{DMU}_{\text {。 }}$ and another one $\left(\mathrm{FS}_{\mathrm{o}}\right)$ quantifying potential shifts in the efficient frontier between these periods. According to these definitions, one could think that the latter term could, in principle, aid to assess overall changes in the efficient frontier. However, it is highly unlikely that this could help reaching a fair conclusion on the shift of the frontier as a whole because this term is calculated for each $\mathrm{DMU}_{\text {。 }}$ (note the subscript in $\mathrm{FS}_{\mathrm{o}}$ ), potentially leading to different $\mathrm{FS}$ values.

To illustrate this, we calculated the term $\mathrm{FS}_{0}$ for each city in the motivating example (see Table 2 ), where $\mathrm{FS}_{0}>1$ indicates that the frontier is regressing, $\mathrm{FS}_{0}=1$ denotes no shift and $\mathrm{FS}_{0}<1$ means the frontier is progressing. Results indicate that the efficient frontier regressed between periods 2 and 3 (i.e. all FS values greater than 1), yet no clear conclusion can be drawn at first glance for changes from period 1 to periods 2 or 3 because the values of FS depend on the DMU assessed, varying from lower to greater than one. This result reflects the fact that regressing and improving parts of the frontiers are actually observed when being compared against each other. Therefore, the resulting FS scores will heavily depend on the particular projection employed, which discards the possibility of relying on average FS values to draw conclusions since there is always the risk of some regions being underrepresented. 


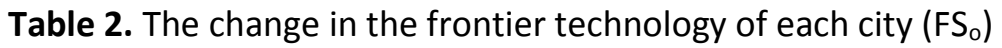

\begin{tabular}{|c|c|c|c|}
\hline \multirow{2}{*}{ Cities } & \multicolumn{3}{|c|}{ FS } \\
\cline { 2 - 4 } & Period 1 to period 2 & Period 2 to period 3 & Period 1 to period 3 \\
\hline A & 1.01 & 1.15 & 1.16 \\
\hline B & 1.03 & 1.41 & 1.24 \\
\hline C & 1.03 & 1.44 & 1.48 \\
\hline D & 1.02 & 1.41 & 1.18 \\
\hline E & 1.00 & 1.32 & 0.95 \\
\hline F & 0.83 & 1.11 & 0.73 \\
\hline G & 1.07 & 1.09 & 1.00 \\
\hline Average & 1.00 & 1.28 & 1.11 \\
\hline
\end{tabular}

Meanwhile, the hypervolume measure is here adopted to investigate how frontiers evolve over time, by comparing the hypervolume values computed for the same intervals and reference boundaries (Fig. 7). Continuing with the motivating example, with focus on the House Price range, the search space is divided into three sub spaces. Similarly, cities were grouped according to three house prices ranges: "lower-cost" houses cities, with house prices ranging from $\$ 297,131(£ 180,000)$ to $\$ 825,365$ ( $£ 500,000)$; “middle-cost" houses cities, from $\$ 825,365$ ( $£ 500,000)$ to $\$ 1,320,584$ ( $₫ 800,000)$; and "higher-cost" houses cities, from $\$ 1,320,584$ ( $£ 800,000)$ to $\$ 2,096,427(£ 1,270,000)$. Results show that cities tended to worsen in the "lower-cost" range from period 1 to period 3, as evidenced by a continuous decline in the hypervolume indicator. On the other hand, the hypervolume in the "middle-cost" range increased over time, while the higher-cost one went up and then down. This regional analysis of the frontier shifts is one additional benefit of our approach over the Malmquist index.

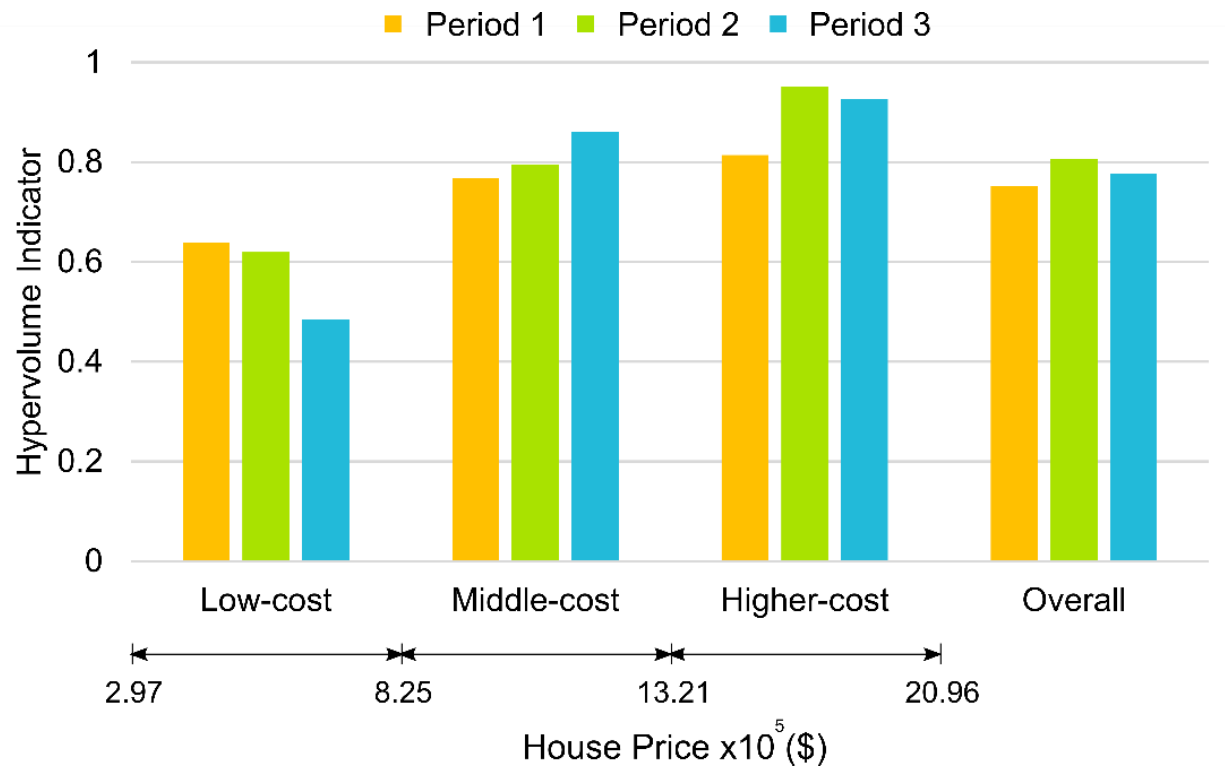

Fig. 7. Hypervolume indicators for the motivating example. 
This motivating example might be straightforward as it deals only with two indicators. The next section explores how the proposed methodology can deal with more complex case studies involving a greater number of sustainability indicators.

\section{Case Study}

In September 2016, experts from five research centres at Imperial College London met to discuss how to collaborate on data science tools for rapid analyses of environmental strains at the urban level. The working group included academics from the Centre for Process Systems Engineering (CPSE), the Grantham Institute: Climate Change and the Environment (GI), the Data Science Institute (DSI), the Institute for Security Science and Technology (ISST), and the Energy Futures Lab (EFL). A number of external stakeholders from government, academia and the private sector joined to provide sectoral perspectives on what products and/or outputs would provide value, with a clear willingness from the Greater London Authority government to support the work. The case study presented next is based on the outcome of this joint multi-disciplinary work, which focused on the sustainability assessment of 32 London boroughs according to eight indicators, including economic, environmental and social metrics. The goal of the analysis is threefold: (i) to identify the best boroughs; (ii) to establish improvement targets for the suboptimal boroughs; and (iii) to study how these boroughs have evolved over time. Note that the proposed method is general enough to be applied to any other spatial and temporal scope and resolutions.

\subsection{Data Collection}

London is the capital and most populous city of the United Kingdom. The political boundaries of London refer to the local metropolitan areas that constitute Greater London. According to the London Government Act 1963, Greater London is organised into 33 local government districts, consisting of 32 London boroughs (which make up the county of Greater London) and the City of London (which is a separate county, but still considered as part of the region). According to 2011 Census, the 32 London boroughs are classified into inner (13) and outer (19) London groups. Inner London boroughs form the interior part of Greater London, while outer London boroughs are located in their surroundings. The population and area of inner London is smaller than that of outer London (i.e. 3,231,901 and $319 \mathrm{~km}^{2}$ for inner London and 4,942,040 and 1,254 $\mathrm{km}^{2}$ for outer London, respectively), but the density of population is much higher (i.e. 10,122 people/ $\mathrm{km}^{2}$ for inner London, and 3,940 people $/ \mathrm{km}^{2}$ for outer London) (Greater London Authority (GLA), 2018). London is also one of the most expensive cities in Europe, where many of the world's wealthiest people live; however, widespread poverty persists due to high levels of inequality in some boroughs (Trust for London, 2018).

To assess the sustainability level of London boroughs, the following eight economic, environmental and social indicators were considered:

1. Economic - related to the economic dimension of the problem:

- Percentage of People with Low Income: percentage of respondents with earnings below the London Living Wage (LLW) and the National Minimum Wage (NMW) taken from the Annual Population Survey. 
- Income of Tax Payers: mean personal income from the Survey of Personal Incomes by Her Majesty's Revenue and Customs (HMRC).

Note that for the time-series calculation, the economic data were adjusted by the Gross Domestic Product (GDP) deflators and converted to the values presented for the reference year 2014.

2. Environmental - related to the environmental impacts generated from the boroughs:

- Carbon Emissions: grand total greenhouse gas emissions from domestic and industrial sectors (i.e. electricity, gas, coal and oil) and all kinds of transportation (i.e. aviation, shipping, railways, diesel, railways electric and road transport), provided by the Greater London Authority. These data were converted to carbon dioxide equivalent $\left(\mathrm{CO}_{2} \mathrm{e}\right)$ prior to the calculations.

- Traffic Flow: estimated traffic volume travelled by all motor vehicles, retrieved from the Department for Transport (DFT) National Road Traffic Survey.

These indicators were measured as a gross amount produced by each borough and then converted to per capita values by dividing by the population in each borough.

3. Social indicators - related to personal well-being of people in the boroughs, estimated from the Annual Population Survey (APS) Well-being dataset. The respondents were asked the following questions, for which responses in the range zero to ten were given, where zero is "not at all" and ten is "completely".

- Anxiety: "Overall, how anxious did you feel yesterday?"

- Happiness: "Overall, how happy did you feel yesterday?"

- Life Satisfaction: "Overall, how satisfied are you with your life nowadays?"

The classification of indicators into the three pillars of sustainability is definitely not unequivocal, since one could always find a rationale to classify a given indicator into multiple categories. For instance, the House Price and People in Low Income could be considered social indicators rather than economic ones. The classification used in this work was inspired by Annex A of ISO 37120, where the most similar indicators were used as reference (e.g. percentage of city population living in poverty similar to Percentage of People in Low Income). It is noted that this classification does not impact the final results, which only depend on whether the indicators are considered inputs or outputs (see Table 3).

Datasets were collected from London Open Datastore (Greater London Authority (GLA), 2019) and pre-processed (missing data interpolation, cleaning, and alignment in temporal scale) by Python scripts. All the data were then imported into a MongoDB cluster, which is a NoSQL database, to support flexible and scalable data query and analysis for large-scale datasets. These indicators could then be extracted from running queries on a MongoDB database. Such data collection and management infrastructure could be applied to other data-driven urban analysis and modelling systems.

\subsection{Assumptions}

In this section, the implementation details and assumptions made are discussed. Each of the 32 London boroughs was modelled as a DMU, while the sustainability indicators were classified as 
either inputs (to be minimised) or outputs (to be maximised) (see Table 3). Inputs include (i) Carbon Emissions, (ii) Traffic Flow, (iii) House Price, (iv) Percentage of People with Low Income and (v) Anxiety. The first three indicators were modelled in turn as discretionary-inputs, since they can be to some extent manipulated via proper regulations. On the other hand, Percentage of People with Low Income and Anxiety were treated as non-discretionary, as they are hard (if not impossible) to vary at will. Outputs include: (vi) Happiness, (vii) Life Satisfaction, and (viii) Income of Tax Payers, which were all considered as non-discretionary outputs.

Table 3. Key characteristics of each performance indicators.

\begin{tabular}{|l|l|c|c|c|}
\hline \multicolumn{1}{|c|}{ Performance Indicators } & \multicolumn{1}{|c|}{ Units } & Category & Input/Output & D/ND \\
\hline Carbon Emissions & $\begin{array}{l}\text { Mean } \\
\text { Tonnes/person }\end{array}$ & Environmental & Input & $\mathrm{D}$ \\
\hline Traffic Flow & $\begin{array}{l}\text { Mean Vehicle } \\
\text { Kilometres/person }\end{array}$ & Environmental & Input & $\mathrm{D}$ \\
\hline House Price & Mean \$/Property & Economic & Input & $\mathrm{D}$ \\
\hline $\begin{array}{l}\text { Percentage People with } \\
\text { Low Income }\end{array}$ & $\begin{array}{l}\text { Mean percentage } \\
\text { of people }\end{array}$ & Economic & Input & $\mathrm{ND}$ \\
\hline Anxiety & Mean score & Social & Input & $\mathrm{ND}$ \\
\hline Happiness & Mean score & Social & Output & $\mathrm{ND}$ \\
\hline Life Satisfaction & Mean score & Social & Output & $\mathrm{ND}$ \\
\hline Income of Tax Payers & Mean \$/person & Economic & Output & $\mathrm{ND}$ \\
\hline
\end{tabular}

\section{Results and Discussion}

\subsection{Efficiency assessment}

The input-oriented VRS DEA model with non-discretionary inputs (M.1) and the superefficiency model (M.2) were applied to the data discussed above. The mathematical model was implemented in GAMS 24.9.2 and solved with CPLEX 12.7.1.0 on an Intel Core i7-3770 processor operating at $3.40 \mathrm{GHz}$. It took around $0.02 \mathrm{CPU}$ seconds to solve every instance.

The DEA results show that there are 20 efficient boroughs in 2012, 25 in 2013 and 23 in 2014. In each period, these efficient boroughs are the members of the set EDMU, which essentially establishes the efficient frontier. The minimum efficiencies across all boroughs were found to be $0.791,0.808$, and 0.767 , for 2012, 2013, and 2014, respectively (see Table 4). Hence, the first thing to notice is that, overall, the boroughs are performing reasonably well, with no single borough showing extremely low efficiency values. This result contrasts with previous findings on other urban systems such as Taiwanese and Chinese cities (Yang et al., 2016; Yin et al., 2014; Yu and Wen, 2010), where efficiency scores as low as $0.514,0.518$ and 0.343 , respectively, were reported. One possible reason

${ }^{3} \mathrm{D}$ is Discretionary variable and ND is Non-discretionary variable. 
for this is that cities spanning over a country's geography might be more heterogeneous due to distinct climatic, cultural, governance and industrial structures in comparison with boroughs of the same city, where a higher homogeneity can be expected.

Table 4. The efficiency and super-efficiency scores of London boroughs in 2012-2014.

\begin{tabular}{|c|c|c|c|c|c|c|}
\hline London Boroughs & Code & Classification $^{\text {ONs }}$ & Sub-regions & 2012 & 2013 & 2014 \\
\hline Barking and Dagenham & BAD & Outer & East & 1.219 & 1.217 & 1.222 \\
\hline Barnet & BAR & Outer & North & 0.939 & 1.000 & 1.000 \\
\hline Bexley & BEX & Outer & East & 1.641 & 1.219 & 1.110 \\
\hline Brent & BRE & Outer & West & 0.876 & 0.871 & 0.878 \\
\hline Bromley & BRO & Outer & South & 2.506 & 2.569 & 2.151 \\
\hline Camden & CAM & Inner & Central & 1.150 & 1.300 & 1.126 \\
\hline Croydon & CRO & Outer & South & 1.027 & 1.089 & 1.032 \\
\hline Ealing & EAL & Outer & West & 0.791 & 0.939 & 0.767 \\
\hline Enfield & ENF & Outer & North & 0.926 & 1.000 & 1.000 \\
\hline Greenwich & GRE & Outer & East & 0.960 & 0.933 & 0.947 \\
\hline Hackney & HAC & Inner & East & 1.111 & 1.155 & 1.086 \\
\hline Hammersmith and Fulham & HAM & Inner & West & 0.923 & 1.000 & 0.824 \\
\hline Haringey & HAY & Inner & North & 1.053 & 1.284 & 1.084 \\
\hline Harrow & HAR & Outer & West & 1.000 & 1.404 & 1.000 \\
\hline Havering & HAV & Outer & East & 1.011 & 1.324 & 1.241 \\
\hline Hillingdon & $\mathrm{HIL}$ & Outer & West & 0.891 & 0.942 & 1.001 \\
\hline Hounslow & $\mathrm{HOU}$ & Outer & West & 0.896 & 0.808 & 0.910 \\
\hline Islington & ISL & Inner & Central & 1.346 & 1.015 & 1.885 \\
\hline Kensington and Chelsea & KEN & Inner & Central & 1.000 & 1.000 & 1.000 \\
\hline Kingston upon Thames & KIN & Outer & South & 0.923 & 0.918 & 0.966 \\
\hline Lambeth & LAM & Inner & Central & 1.000 & 1.803 & 0.967 \\
\hline Lewisham & LEW & Inner & East & 1.069 & 1.266 & 1.187 \\
\hline Merton & MER & Outer & South & 1.024 & 1.034 & 1.062 \\
\hline Newham & NEW & Inner & East & 0.986 & 1.228 & 1.191 \\
\hline Redbridge & RED & Outer & East & 1.225 & 1.373 & 1.030 \\
\hline Richmond upon Thames & $\mathrm{RIC}$ & Outer & West & 1.000 & 1.000 & 1.000 \\
\hline Southwark & SOU & Inner & Central & 1.044 & 0.965 & 1.410 \\
\hline Sutton & SUT & Outer & South & 1.047 & 1.032 & 1.112 \\
\hline Tower Hamlets & TOW & Inner & East & 0.906 & 1.033 & 0.967 \\
\hline Waltham Forest & WAL & Outer & East & 1.123 & 1.173 & 1.003 \\
\hline Wandsworth & WAN & Inner & South & 1.000 & 1.417 & 1.354 \\
\hline Westminster & WES & Inner & Central & 0.904 & 1.000 & 0.919 \\
\hline
\end{tabular}

${ }^{\text {oNs }}$ Classification by the Office for National Statistics and the 2001 Census.

According to the efficiency and super-efficiency scores during 2012-2014 presented in Table 4, the boroughs can be divided into three categories: (i) always efficient, (ii) efficient/inefficient, and (iii) always inefficient. There are 18 boroughs (more than half) that are efficient in all of the time periods. Among them, Bromley performs outstandingly well, and is the borough with the highest super-efficiency score throughout the whole period. This is mostly due to its high Happiness and Life 
Satisfaction scores across 2012-2014. In addition, it also shows a good compromise between the other inputs and outputs, and never displays extremely poor performance in any indicator (i.e. never among the worst eight boroughs in any period or indicator). In terms of spatial distribution, most of the boroughs that are always efficient are primarily located in the east and the south London, as depicted in Fig. 8, while 11 out of these 18 boroughs are outer London boroughs.

There are nine boroughs that move from efficient to inefficient or vice-versa from one period to the other. Six of them are inner London boroughs (Hammersmith and Fulham, Lambeth, Southwark, Tower Hamlets, Westminster, and Newham), while three are outer London boroughs (Barnet, Enfield, and Hillingdon). Most of these boroughs are mainly located in the north and central London.

Finally, there are five boroughs that are always inefficient (Brent, Ealing, Greenwich, Hounslow and Kingston upon Thames). These boroughs perform very poorly in at least one indicator in every period (i.e. always among the worst ten boroughs). For example, Brent is the worst-performer in terms of economic indicators, as it shows the highest ratio of expense per income (i.e. ratio House Price to Income Tax Payer) in every year from 2012 to 2014. In terms of spatial distribution, all the boroughs found in this category are outer London, while most of them are located in the west London.

Hence, there seems to be a strong spatial component behind the efficiency scores shown by the boroughs based on their geographical location; the western outer London boroughs are the worstperforming ones and the eastern and the southern outer London boroughs are the best-performing. This result is aligned with what has been previously reported on analysing Chinese cities, where higher efficiencies were observed for south-eastern settlements owing to them belonging to coastal city agglomerations (Yu and Wen, 2010). In the case of London, eastern boroughs are closer to the coast but, certainly, cannot be deemed coastal; therefore, other factors potentially explaining their high efficiency scores need to be explored. For instance, the majority of the east and the south London boroughs have cheaper House Price and show the relatively low ratio of expense per income, which could suggest high purchasing power. In contrast, the west London boroughs show, in average, the highest ratio of expense per income, implying that they have more financial burden compared to the other sub-regions. 

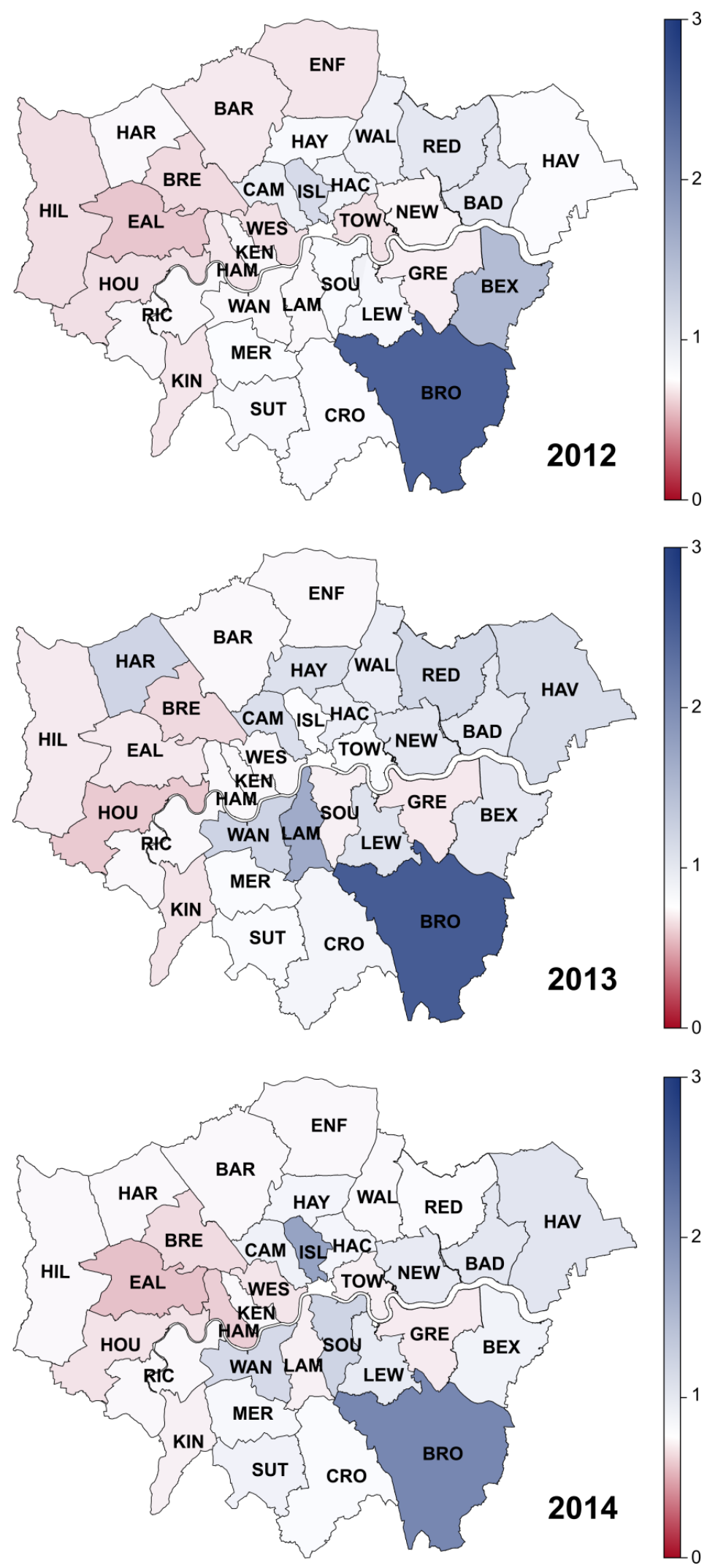

Fig. 8. Spatial heat-map showing the super-efficiency score of London boroughs from 2012 to 2014. Borough codes as given in Table 4.

\subsection{Inefficiency assessment}


DEA was applied next to compute improvement targets for the inefficient boroughs as shown in Eqs. (4) and (5). As an example, results for 2014 are shown in Fig. 9, where indicators are displayed in the vertical axis and inefficient boroughs are presented in the horizontal one. Taking Ealing as an example, which is the worst borough with an efficiency score of 0.767 , the model suggests reducing Carbon Emissions, Traffic Flow, and House Price by approximately 27\%, 23\% and 23\%, respectively; note that these indicators are the only discretionary ones that can be manipulated to improve the efficiency scores.

It is important to note that the model might suggest improvements in the non-discretionary inputs and outputs due to non-zero slacks in the optimal solution. These slacks, which do not affect the efficiency scores, ultimately reflect exogenous deficiencies compared to the efficient boroughs (see Supplementary Material for further details).

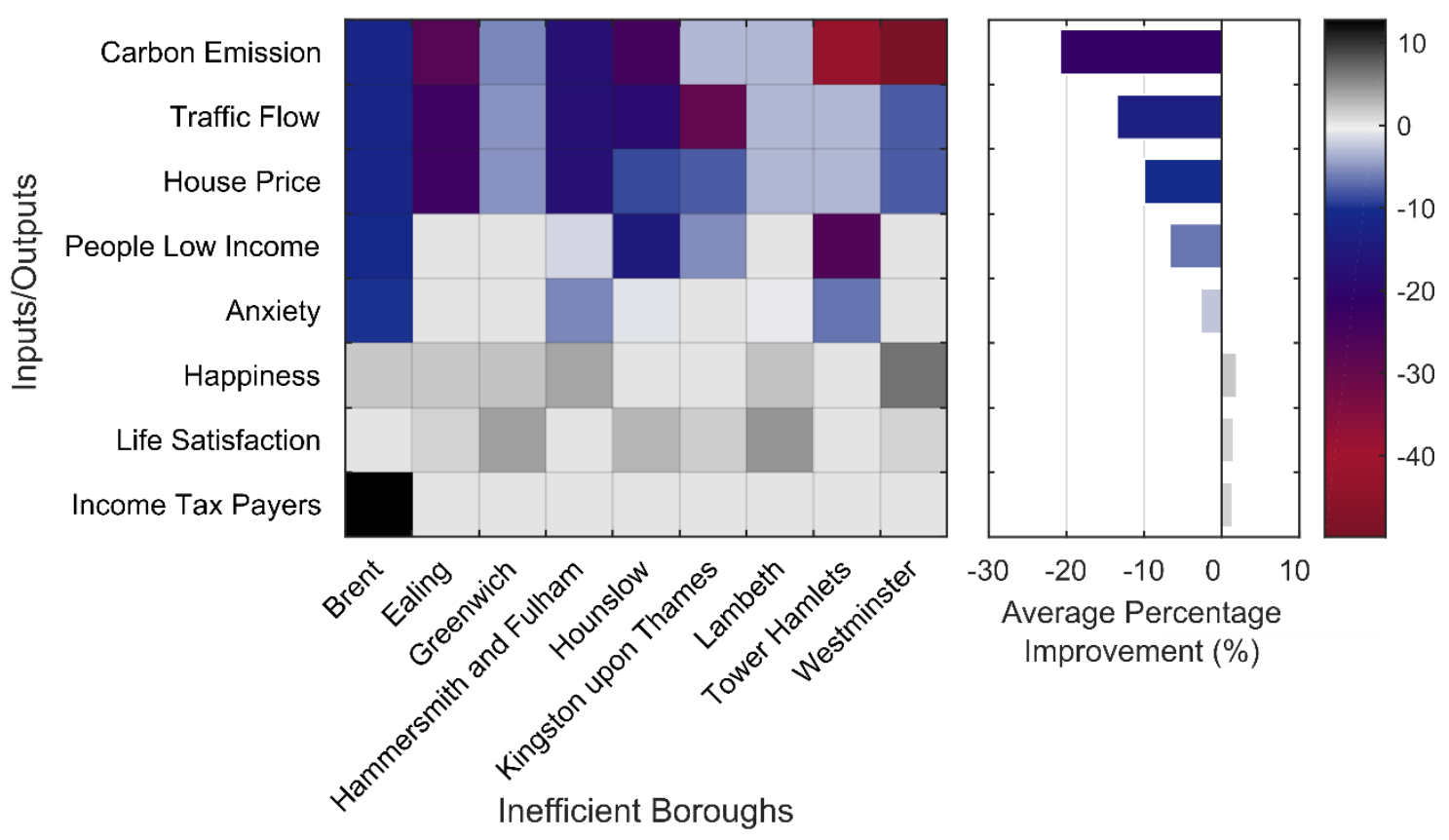

Fig. 9. Heatmap of \%improvement of the inefficient boroughs and average \%improvement of each indicators of in 2014.

Analysing the improvement required in every input/output across all the inefficient boroughs, it is found that Carbon Emissions is the most critical indicator, with an average improvement percentage required of around $21 \%$ (see Fig. 9). This might be explained by heating demand from buildings -one of the major contributors to carbon emissions in urban areas- and its link with the age of dwellings in affected boroughs. Older dwellings typically feature poorer thermal insulation compared to modern buildings, thus resulting in higher heating demands and, consequently, larger carbon emissions. It is therefore not surprising that dwellings in boroughs requiring the most significant improvements in carbon emissions were mainly built either before 1900 (e.g. $46 \%$ of dwellings in Westminster) or between 1930-1939 (e.g. 26\% of dwellings in Ealing and 23\% of those in Hounslow) according to official data (Greater London Authority (GLA), 2019) (data set "dwelling build period and property type"). 
Finally, the attention is turned towards how inefficient boroughs could become efficient by mimicking the behaviour of the efficient ones. Recall that the improvement targets established for each inefficient unit (shown in Fig. 10) are obtained from a linear combination of a set of efficient units, referred to as the peer group of the inefficient DMU being projected. For instance, the efficient targets in 2014 for Kingston upon Thames come from a linear combination of Barnet, Bromley, Harrow, and Kensington and Chelsea, with linear weights of 0.059, 0.831, 0.086, and 0.024, respectively. This can be interpreted in the following manner: Kingston upon Thames is performing worse than Barnet, Bromley, Harrow, and Kensington and Chelsea; however, it could become optimal by using a similar infrastructure and operating in a similar way as the aforementioned boroughs, with special focus on Bromley, as this borough shows the largest linear coefficient. Harrow is the borough most widely used as reference, while there are six efficient boroughs that are never used by any inefficient borough (i.e. Enfield, Hillingdon, Redbridge, Southwark, Sutton and Waltham Forest).

On a more practical side, the improvement targets and the members of the peer group of each inefficient borough could be used to guide the development of target regulations. First, policies need to be developed to vary the values of the performance metrics. For instance, reduce Carbon Emissions, policies could focus on adopting more environmentally friendly vehicles, improving public transport services (e.g. electrification) or increasing green areas. On the other hand, policies aiming at reducing the Traffic Flow could more efficiently manage queues, promote campaigns to incentivise walking and cycling and improve public transport. Meanwhile, House Prices could be lowered through taxes and/or subsides and more social housing. When delineating such policies, the current data of peer boroughs (e.g. number of underground and bus stations in the peer group) could be used as a starting point.

In essence, after establishing targets for an inefficient borough, policy-makers should analyse its peer group members to find effective ways to make it more efficient. Hence, both pieces of information can be very valuable to support decision-making in improving the efficiency of urban systems and the life quality of its population. 


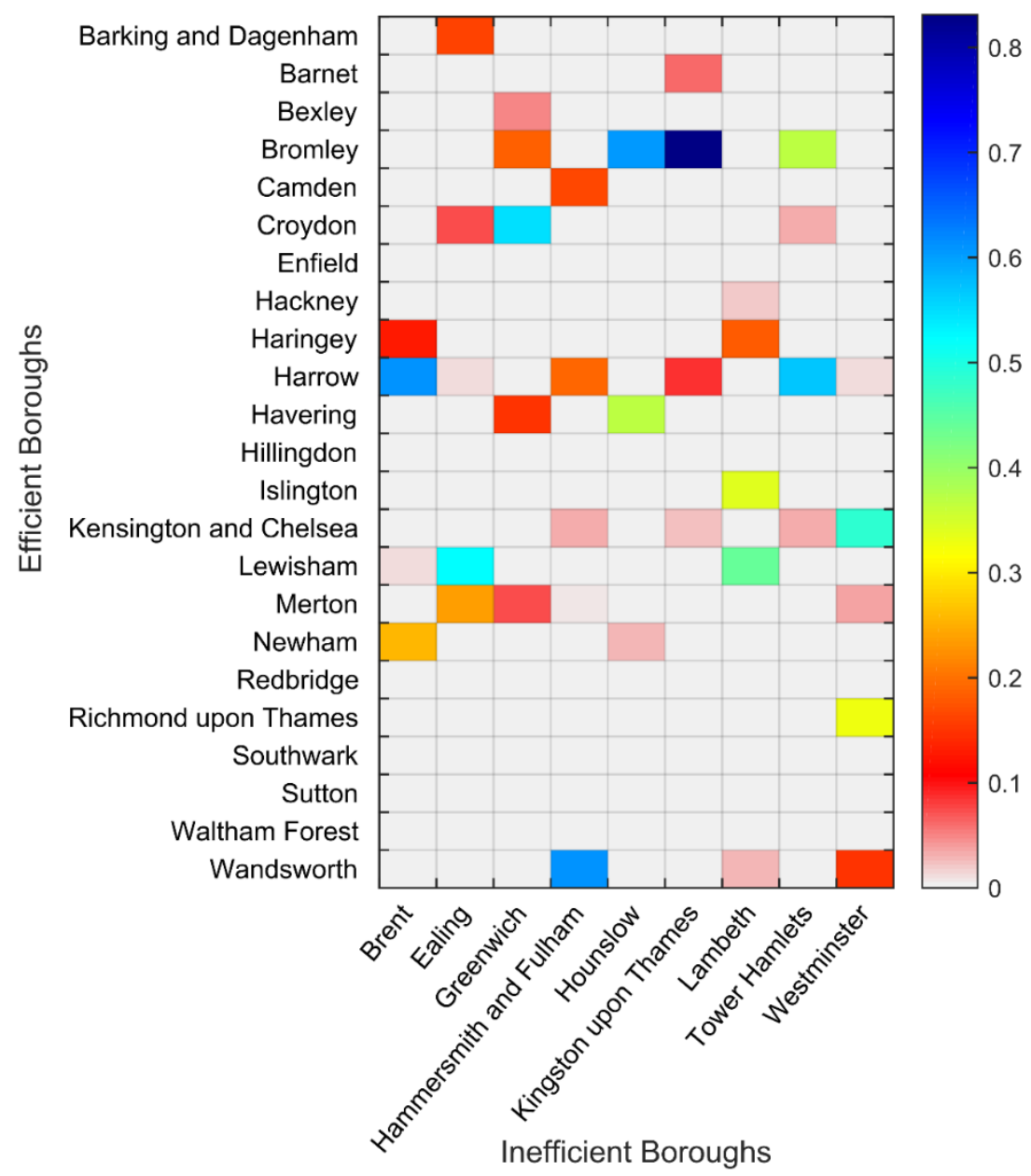

Fig. 10. Linear weight of peers for each inefficient borough for 2014.

\subsection{Temporal analysis of the efficiency frontiers}

The DEA-based hypervolume algorithm (M.3) with the set EDMU obtained from M.1 was implemented in GAMS 24.9.2 in the same computer, taking around 0.03 CPU seconds to solve each LP-based test. 1,000 pseudorandom points were generated between the lower and upper bounds (i.e. minimum and maximum values) of each indicator (i.e. input/output) across the period 2012-2014. Furthermore, the hypervolume was calculated in two different ways: (i) for all the data, and (ii) for three House Price ranges (i.e. "lower-cost" houses boroughs with prices from $\$ 297,131(£ 180,000)$ to $\$ 825,365$ ( $£ 500,000)$, "middle-cost" houses boroughs from $\$ 825,365$ ( $£ 500,000)$ to $\$ 1,320,584$ $(£ 800,000)$, and "higher-cost" houses boroughs from $\$ 1,320,584(£ 800,000)$ to $\$ 2,096,427$ $(f 1,270,000)$. Overall, the efficient frontier of 2014 shows the best performance, with a hypervolume indicator of 0.255 , followed by 2013 and 2012, with 0.183 and 0.165 , respectively (see Fig. 11). This means that, overall, the efficient frontier of London boroughs improved over time. The shift in the efficient frontier can be explained, to some extent, by observing the changes over time in the best values in each indicator (i.e. the minimum value for inputs and the maximum value for outputs). In particular, the best performance for the majority of indicators improved over time (e.g. Percentage of 
People with Low Income and Carbon Emissions reduced by 15\% and 13\% in 2014 compared to 2012, respectively), while the only one worsening was House Price, which increased by $14 \%$ in the same period.

Considering the boroughs according to their House Price range, the "lower-cost" group first worsened and then improved (from 0.046 in 2012, to 0.041 in 2013 and finally to 0.059 in 2014), while the other two groups increased monotonically in the same time horizon, with total percentage improvements in 2012-2014 of 47 and 61\%, respectively. In the low-cost House Price range, the frontier remained almost the same between 2012 and 2014; in this period drops in the best values of indicators like Percentage of People with Low Income (54\%), Income Tax Payer (18\%), and House Price (14\%) were counterbalanced by improvements in the remaining indicators (between 1 and $13 \%$ in their top values).

In the middle-cost House Price range, the best values for all the indicators improved from 2012 to 2014, with significant reductions of 52\% in Carbon Emissions, 31\% in Percentage of People with Low Income, and $21 \%$ in Anxiety. In the high-cost House Price range, most indicators showed substantial improvements (e.g. 59\% in Carbon Emissions, 46\% in House Price, $43 \%$ in Traffic Flow, and 31\% in Percentage of People with Low Income) with the only exception being a $45 \%$ deterioration in Income Tax Payer.

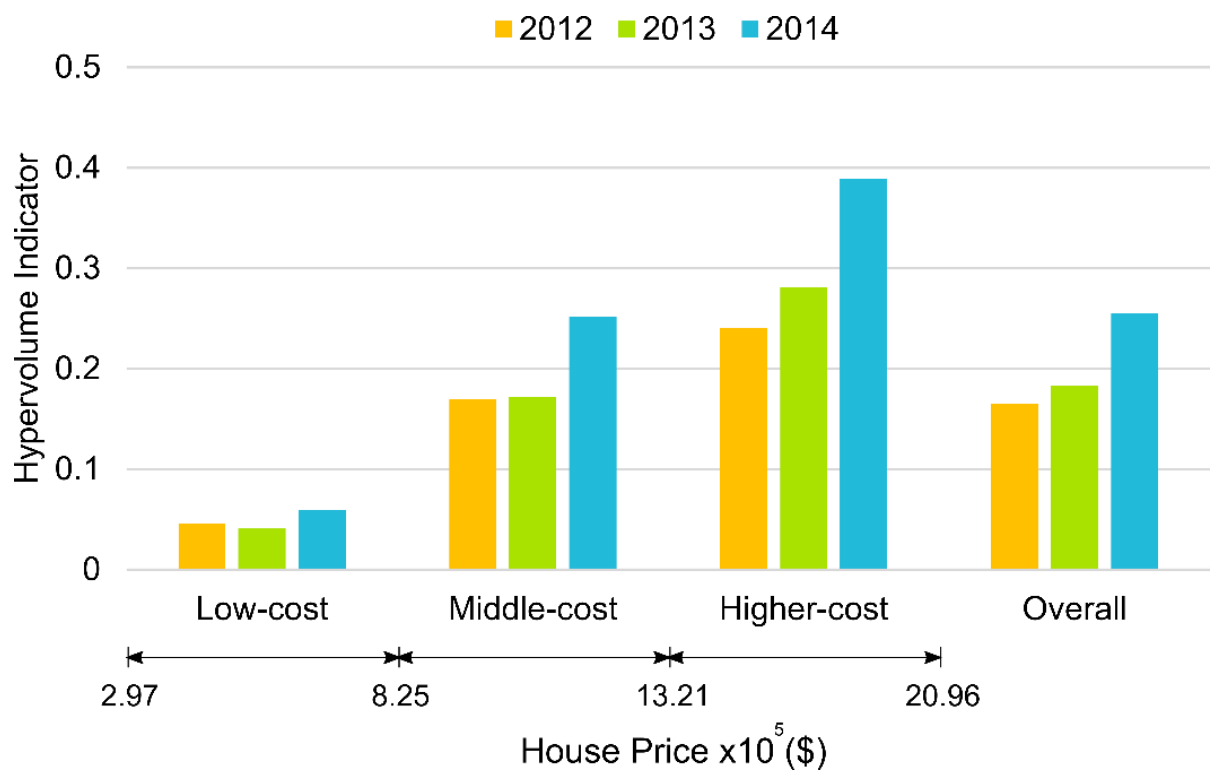

Fig. 11. Hypervolume indicators for the case study

\section{Conclusions}

Optimising urban systems is key to achieve the Sustainable Development Goals, as they contribute significantly to the environmental footprint of densely populated urban centres. In this work, a new method for the temporal sustainability assessment of urban systems is proposed and applied to the evaluation of 32 London boroughs in 2012-2014 considering eight economic, environmental and social indicators. The method proposed combines DEA with the hypervolume concept to: (i) identify the best (most efficient) urban systems; (ii) propose improvement targets for 
the suboptimal ones; and (iii) understand how the performance of a group of urban systems evolves over time.

Results reveal that, on average, the level of efficiency among boroughs is quite high and that this efficiency seems to be linked to the boroughs' spatial location, where the best performance is observed in eastern and southern outer London boroughs and the worst in western outer London boroughs. This might be due to the former showing comparatively cheaper houses and lower ratio of expense per income, which suggests, in turn, a larger purchasing power. Regarding the temporal evolution, it was found that, as a whole, the boroughs have improved over time, resulting in an efficient frontier of higher quality. This improvement was mainly driven by a reduction in Carbon Emissions and Percentage of People with Low Income, while it was partially counterbalanced by higher House Price.

The method proposed allows classifying boroughs into efficient and inefficient, establishing improvement targets for the inefficient boroughs and identifying peers (i.e. to be used as benchmark) for each of them. According to this approach, the indicator that need to be improved the most is Carbon Emissions (with an average improvement required of $21 \%$ ).

This analysis highlights several weaknesses to be addressed by policy makers to develop more effective regulations and policies at the municipal level. When delineating such policies, reference boroughs could be taken as starting point. For instance, the number of underground and bus stations per $\mathrm{m}^{2}$ in reference boroughs could serve as a basis to improve the Traffic Flow of inefficient boroughs. By using the proposed approach, more informed decisions can be taken while improving our understanding on the sources of inefficiencies and potential areas of improvement.

\section{Acknowledgements}

This work is a product of two EPSRC Institutional Sponsorship Funding Scheme projects "CITY-DEACity efficiency analysis through Data Envelopment Analysis" to G.G. (PI), T.G., N.S. and S.A. and "Data science tools for rapid analyses of environmental strain across temporal and spatial scales" to M.S. (PI) and Y.G.

\section{References}

Babazadeh, R., Razmi, J., Rabbani, M., Pishvaee, M.S., 2017. An integrated data envelopment analysis-mathematical programming approach to strategic biodiesel supply chain network design problem. J. Clean. Prod. 147, 694-707. https://doi.org/10.1016/j.jclepro.2015.09.038

Beume, N., Naujoks, B., Emmerich, M., 2007. SMS-EMOA: Multiobjective selection based on dominated hypervolume. Eur. J. Oper. Res. 181, 1653-1669. https://doi.org/10.1016/j.ejor.2006.08.008

Beume, N., Rudolph, G., 2006. Faster S-Metric Calculation by Considering Dominated Hypervolume as Klee's Measure Problem, in: The Second IASTED International Conference on Computational Intelligence. https://doi.org/10.17877/DE290R-12786 
Bratley, P., Fox, B.L., Niederreiter, H., 1992. Implementation and tests of low-discrepancy sequences. ACM Trans. Model. Comput. Simul. 2, 195-213. https://doi.org/10.1145/146382.146385

Caves, D.W., Christensen, L.R., Diewert, W.E., 1982. The Economic Theory of Index Numbers and the Measurement of Input, Output, and Productivity. Econometrica 50, 1393-1414. https://doi.org/10.2307/1913388

Charnes, A., Cooper, W.W., Li, S., 1989. Using data envelopment analysis to evaluate efficiency in the economic performance of chinese cities. Socioecon. Plann. Sci. 23, 325-344. https://doi.org/10.1016/0038-0121(89)90001-3

Charnes, A., Cooper, W.W., Rhodes, E., 1978. Measuring the efficiency of decision making units. Eur. J. Oper. Res. 2, 429-444. https://doi.org/10.1016/0377-2217(78)90138-8

Chatterjee, M., 2003. Modulation masking in cochlear implant listeners: envelope versus tonotopic components. J. Acoust. Soc. Am. 113, 2042-2053. https://doi.org/10.1121/1.1555613

Chen, Y., 2005. Measuring super-efficiency in DEA in the presence of infeasibility. Eur. J. Oper. Res. 161, 545-551. https://doi.org/10.1016/j.ejor.2003.08.060

Chen, Y., Cook, W.D., Li, N., Zhu, J., 2009. Additive efficiency decomposition in two-stage DEA. Eur. J. Oper. Res. 196, 1170-1176. https://doi.org/10.1016/j.ejor.2008.05.011

Cook, W.D., Tone, K., Zhu, J., 2014. Data envelopment analysis: Prior to choosing a model. Omega 44, 1-4. https://doi.org/10.1016/j.omega.2013.09.004

Cooper, W.W., Seiford, L.M., Tone, K., 2007. Data Envelopment Analysis: A Comprehensive Text with Models, Applications, References and DEA-Solver Software. Springer Science \& Business Media. https://doi.org/10.1007/978-0-387-45283-8

Copado-Méndez, P.J., Pozo, C., Guillén-Gosálbez, G., Jiménez, L., 2016. Enhancing the $\varepsilon$-constraint method through the use of objective reduction and random sequences: Application to environmental problems. Comput. Chem. Eng. 87, 36-48. https://doi.org/10.1016/j.compchemeng.2015.12.016

De Koeijer, T.J., Wossink, G.A.A., Struik, P.C., Renkema, J.A., 2002. Measuring agricultural sustainability in terms of efficiency: The case of Dutch sugar beet growers. J. Environ. Manage. 66, 9-17. https://doi.org/10.1006/jema.2002.0578

Doyle, J., Green, R., 1993. Data envelopment analysis and multiple criteria decision making. Omega 21, 713-715. https://doi.org/10.1016/0305-0483(93)90013-B

Egilmez, G., Kucukvar, M., Tatari, O., 2013. Sustainability assessment of U.S. manufacturing sectors: An economic input output-based frontier approach. J. Clean. Prod. 53, 91-102. https://doi.org/10.1016/j.jclepro.2013.03.037

Everson, R.M., Fieldsend, J.E., Singh, S., 2002. Full elite sets for multi-objective optimisation, in: Adaptive Computing in Design and Manufacture V. Springer, pp. 343-354. https://doi.org/10.1007/978-0-85729-345-9_29

Ewertowska, A., Galán-Martín, A., Guillén-Gosálbez, G., Gavaldá, J., Jiménez, L., 2015. Assessment of the environmental efficiency of the electricity mix of the top European economies via data envelopment analysis. J. Clean. Prod. 116, 13-22. https://doi.org/10.1016/j.jclepro.2015.11.100 
Ewertowska, A., Pozo, C., Gavaldà, J., Jiménez, L., Guillén-Gosálbez, G., 2017. Combined use of life cycle assessment, data envelopment analysis and Monte Carlo simulation for quantifying environmental efficiencies under uncertainty. J. Clean. Prod. 166, 771-783. https://doi.org/10.1016/j.jclepro.2017.07.215

Färe, R., Grosskopf, S., 1992. Malmquist productivity indexes and Fisher ideal indexes. Econ. J. 102, 158-160. https://doi.org/10.2307/2234861

Färe, R., Grosskopf, S., Lindgren, B., Roos, P., 1994. Productivity Developments in Swedish Hospitals: A Malmquist Output Index Approach, in: Data Envelopment Analysis: Theory, Methodology, and Applications. Springer, pp. 253-272. https://doi.org/10.1007/978-94-011-0637-5_13

Fernández, D., Pozo, C., Folgado, R., Guillén-Gosálbez, G., Jiménez, L., 2017. Multiperiod model for the optimal production planning in the industrial gases sector. Appl. Energy 206, 667-682. https://doi.org/10.1016/j.apenergy.2017.08.064

Gomes, E.G., Soares De Mello, J.C.C.B., E Souza, G.D.S., Angulo Meza, L., Mangabeira, J.A.D.C., 2009. Efficiency and sustainability assessment for a group of farmers in the Brazilian Amazon. Ann. Oper. Res. 169, 167-181. https://doi.org/10.1007/s10479-008-0390-6

Goodland, R., Daly, H., 1996. Environmental sustainability: Universal and non-negotiable. Ecol. Appl. 6, 1002-1017. https://doi.org/10.2307/2269583

Greater London Authority (GLA), 2019. London Datastore [WWW Document]. URL https://data.london.gov.uk/dataset/property-build-period-Isoa (accessed 5.22.19).

Greater London Authority (GLA), 2018. Land Area and Population Density, Ward and Borough [WWW Document]. URL https://data.london.gov.uk/dataset/land-area-and-populationdensity-ward-and-borough (accessed 11.8.18).

HM Revenue \& Customs, G.U., 2019. Sterling value of currency unit $f$ (average for the year to 31 December 2014) [WWW Document]. URL https://www.gov.uk/government/uploads/system/uploads/attachment_data/file/421061/aver age310315-1.csv/preview (accessed 5.15.19).

Huang, S.L., Wong, J.H., Chen, T.C., 1998. A framework of indicator system for measuring Taipei's urban sustainability. Landsc. Urban Plan. 42, 15-27. https://doi.org/10.1016/S01692046(98)00054-1

Klopp, G.A., 1985. The Analysis of the Efficiency of Productive Systems with Multiple Inputs and Outputs. University of Illinois at Chicago.

Malmquist, S., 1953. Index numbers and indifference surfaces. Trab. estadística 4, 209-242. https://doi.org/10.1007/BF03006863

Martín-Gamboa, M., Iribarren, D., García-Gusano, D., Dufour, J., 2017. A review of life-cycle approaches coupled with data envelopment analysis within multi-criteria decision analysis for sustainability assessment of energy systems. J. Clean. Prod. 150, 164-174. https://doi.org/10.1016/J.JCLEPRO.2017.03.017

Reynolds, D., Thompson, G.M., 2007. Multiunit restaurant productivity assessment using threephase data envelopment analysis. Hosp. Manag. 26, 20-32. https://doi.org/10.1016/j.ijhm.2005.08.004

Seiford, L.M., Zhu, J., 1999. Infeasibility of super-efficiency data envelopment analysis models. Inf. 
Syst. Oper. Res. 37, 174-187. https://doi.org/10.1080/03155986.1999.11732379

Sueyoshi, T., Wang, D., 2014. Sustainability development for supply chain management in U.S. petroleum industry by DEA environmental assessment. Energy Econ. 46, 360-374. https://doi.org/10.1016/j.eneco.2014.09.022

Sueyoshi, T., Yuan, Y., Goto, M., 2017. A literature study for DEA applied to energy and environment. Energy Econ. 62, 104-124. https://doi.org/10.1016/j.eneco.2016.11.006

Tajbakhsh, A., Hassini, E., 2015. A data envelopment analysis approach to evaluate sustainability in supply chain networks. J. Clean. Prod. 105, 74-85. https://doi.org/10.1016/j.jclepro.2014.07.054

Thompson, R.G., Langemeier, L.N., Lee, C.T., Lee, E., Thrall, R.M., 1990. The role of multiplier bounds in efficiency analysis with application to Kansas farming. J. Econom. 46, 93-108. https://doi.org/10.1016/0304-4076(90)90049-Y

Tone, K., 2001. Slacks-based measure of efficiency in data envelopment analysis. Eur. J. Oper. Res. 130, 498-509. https://doi.org/10.1016/S0377-2217(99)00407-5

Trust for London, 2018. Income inequality by borough [WWW Document]. URL https://www.trustforlondon.org.uk/data/income-inequality-borough/ (accessed 11.8.18).

TWI2050 - The World in 2050, 2018. Transformations to Achieve the Sustainable Development Goals. Report prepared by The World in 2050 initiative. Laxenburg, Austria.

Wang, K., Wei, Y.M., 2014. China's regional industrial energy efficiency and carbon emissions abatement costs. Appl. Energy 130, 617-631. https://doi.org/10.1016/j.apenergy.2014.03.010

Yang, W.C., Lee, Y.M., Hu, J.L., 2016. Urban sustainability assessment of Taiwan based on data envelopment analysis. Renew. Sustain. Energy Rev. 61, 341-353.

https://doi.org/10.1016/j.rser.2016.04.015

Yin, K., Wang, R., An, Q., Yao, L., Liang, J., 2014. Using eco-efficiency as an indicator for sustainable urban development: A case study of Chinese provincial capital cities. Ecol. Indic. 36, 665-671. https://doi.org/10.1016/j.ecolind.2013.09.003

Yu, Y., Wen, Z., 2010. Evaluating China's urban environmental sustainability with Data Envelopment Analysis. Ecol. Econ. 69, 1748-1755. https://doi.org/10.1016/J.ECOLECON.2010.04.006

Zhang, B., Bi, J., Fan, Z., Yuan, Z., Ge, J., 2008. Eco-efficiency analysis of industrial system in China: A data envelopment analysis approach. Ecol. Econ. 68, 306-316.

https://doi.org/10.1016/j.ecolecon.2008.03.009

Zhou, P., Ang, B.W., Poh, K.L., 2008. A survey of data envelopment analysis in energy and environmental studies. Eur. J. Oper. Res. 189, 1-18. https://doi.org/10.1016/j.ejor.2007.04.042

Zitzler, E., Brockhoff, D., Thiele, L., 2007. The Hypervolume Indicator Revisited: On the Design of Pareto-compliant Indicators Via Weighted Integration, in: Evolutionary Multi-Criterion Optimization. EMO 2007. Lecture Notes in Computer Science. Springer, pp. 862-876. https://doi.org/10.1007/978-3-540-70928-2_64

Zitzler, E., Thiele, L., 1998. Multiobjective optimization using evolutionary algorithms - A comparative case study, in: Parallel Problem Solving from Nature - PPSN V. pp. 292-301.

https://doi.org/10.1007/BFb0056872 
Zitzler, E., Thiele, L., Laumanns, M., Fonseca, C.M., Da Fonseca, V.G., 2003. Performance assessment of multiobjective optimizers: An analysis and review. IEEE Trans. Evol. Comput. 7, 117-132. https://doi.org/10.1109/TEVC.2003.810758

Zofío, J.L., Prieto, A.M., 2001. Environmental efficiency and regulatory standards: The case of CO2 emission from OECD industries. Resour. Energy Econ. 23, 63-83. https://doi.org/10.1016/S0928-7655(00)00030-0

Zurano-Cervelló, P., Pozo, C., Mateo-Sanz, J.M., Jiménez, L., Guillén-Gosálbez, G., 2018. Ecoefficiency assessment of EU manufacturing sectors combining input-output tables and data envelopment analysis following production and consumption-based accounting approaches. J. Clean. Prod. 174, 1161-1189. https://doi.org/10.1016/j.jclepro.2017.10.178 